\title{
With a Little Help from My Friends? \\ Quality of Social Networks, Job Finding and Job Match Quality ${ }^{\S}$
}

\section{(published in: European Economic Review 78 (2015) 55-75)}

\author{
Lorenzo Cappellari \\ Università Cattolica Milano
}

\author{
Konstantinos Tatsiramos \\ University of Nottingham and IZA
}

March 2015

\begin{abstract}
This paper studies the effect of network quality on job finding and job match quality using longitudinal data and a direct measure of network quality, which is based on the employment of friendship ties. Various identification strategies provide robust evidence that a higher number of employed contacts increases the job finding rate. Network quality also increases wages for highskilled workers forming networks with non-familial contacts. Instead, for low-skilled workers, more employed familial contacts lead to a negative but not significant effect on wages. These findings reconcile previous mixed evidence of network effects on wages, indicating heterogeneity by skill level and relationship type.
\end{abstract}

Keywords: Social Contacts, Unemployment, Friendship Ties, Wages, Employment Stability JEL: J64, J63, J21, J31, L14

\footnotetext{
$\S$ We thank the editor, an associate editor and two anonymous referees for very helpful comments and suggestions. A previous version of this paper has been circulated as an IZA Discussion Paper No. 5240 with the title "Friends' Networks and Job Finding Rates".

Contact: Lorenzo Cappellari, Università Cattolica, Largo Gemelli 1, 20123, Milan Italy, email: lorenzo.cappellari@unicatt.it; Konstantinos Tatsiramos, University of Nottingham, School of Economics, University Park, Nottingham, NG7 2RD, UK, and Institute for the Study of Labor (IZA), Bonn, e-mail: Konstantinos.Tatsiramos@nottingham.ac.uk.
} 


\section{Introduction}

Informal contacts through social networks have long been considered an important source of information in the job search process. Survey evidence gathered across countries and over time has consistently indicated that between one third and one half of job matches are created through friends and relatives (see e.g. Ioannides and Loury, 2004, and Topa, 2011). Despite the importance of the use of contacts in job search, there is limited empirical evidence on the effect of network quality on labor market outcomes. Recent theoretical studies have focused on the employment status of network members as the relevant measure of network quality for understanding the effectiveness of social contacts as a job search channel (e.g. Calvó-Armengol and Jackson, 2004; Fontaine, 2008; Galeotti and Merlino, 2014). The main insight from this literature is that a higher employment rate within the network of social contacts increases the chances of a successful job match for non-employed network members through the transmission of information about job opportunities. The effect of network quality on job match quality, however, depends on the degree of homophily, which is the tendency of individuals to befriend others who are similar to themselves (e.g. Bentolila et al. 2010; Horvath, 2014).

In this paper, we contribute to the empirical literature by studing how the employment status of friendship ties affects the job finding probability, starting wages and employment stability, using longitudinal data from the British Household Panel Survey (BHPS). There are three main objectives of the paper: (i) to measure the effect of network quality on the job finding probability; (ii) to measure the effect of network quality on the quality of job matches among those who find a job; and (iii) to measure differences in the effect of network quality by the type of contacts (familial vs. nonfamilial) and by worker skill level.

Identifying network effects on labor market outcomes is challenging due to non-random selection into networks, simultaneity, and the presence of common shocks. We present an empirical model of individual employment transitions, which provides a general analytical framework, and we address these issues using three identification strategies. Each of the three strategies we propose is derived from the general framework by imposing different assumptions. The first is a fixed effects estimator, which partials out time-invariant unobserved heterogeneity by exploiting the availability of multiple individual transitions in the data, and time variation of network quality. The second is a 
semi-parametric correlated random effects estimator of the transition into employment, which takes into account initial conditions and models the potential correlation of network quality with unobserved heterogeneity. The third is an instrumental variable (IV) estimator, which addresses endogeneity due to reverse causality, non-random selection, and other correlated effects from all sources of unobserved heterogeneity, not only time-invariant ones.

Across all models we find consistently that better network quality through a higher number of employed friends increases the job finding rate. From our preferred model of correlated random effects with initial conditions, we find that an additional employed friend increases the transition probability from non-employment to employment by 3.1 percentage points, or by 15 percent. We also provide evidence which suggests that the effect of network quality on job finding is not driven by local correlated shocks.

Extending our analyses to match quality, which is measured by wages and employment stability, we find a smaller effect of an additional employed friend on both measures once we control for selection into employment and unobserved heterogeneity. There is, however, substantial heterogeneity by skill level and type of relationship. In particular, an additional employed nonrelative increases the re-employment wage of high-skilled workers by 6.1 percent. Instead, an additional employed relative reduces the re-employment wage of low-skilled workers by 4.3 percent, but this effect is not statistically significant. We find similar patterns of heterogeneity by skill level and type of relationship also for the effect of network quality on employment stability, but these results are not statistically significant when controlling for selection into employment and unobserved heterogeneity.

The heterogeneity of the effect of network quality on job match quality is consistent with the theoretical litetarute suggesting that the matching effect of networks depends on the degree of homophily between network members, where homophily reduces skill mismatch. Our data indicate higher similarity of personal attributes within networks of skilled workers and non-relatives. These findings on match quality reconcile mixed evidence of the existing literature on the use of social contacts as a search channel, indicating heterogeneity by skill level and the type of relationship.

The remainder of the paper is organized as follows. In Section 2 we discuss the theoretical framework which links the employment stauts of social contacts to job finding and match quality. In 
Section 3 we describe the data and present some sample summary statistics. In Section 4 we outline the empirical framework and discuss the three strategies we propose for identifying the effect of network quality on job finding rates. In Section 5 we present the findings and sensitivity analyses on job finding from each model separately, while in Section 6 we present the analysis and the results for the effect of network quality on job match quality. We provide concluding remarks in Section 7.

\section{Theoretical Framework and Related Literature}

There are two main functions of networks in the labor market: (i) to transmit information about job opportunities; and (ii) to transmit information about the productivity of workers and the quality of worker-job match. The theoretical framework we adopt to motivate our empirical analysis is based on the role of social networks in reducing search frictions by spreading information about job opportunities (e.g. Calvó-Armengol, 2004; Calvó-Armengol and Jackson, 2004; Calvó-Armengol and Zenou, 2005; Ioannides and Soetevent, 2006; Fontaine, 2008; Cahuc and Fontaine, 2009; Bramoullé and Saint-Paul, 2009; Galeotti and Merlino, 2014). ${ }^{1}$ In this framework, both employed and unemployed workers receive information randomly about job vacancies, and each individual is connected with others within a network. Job offers received by unemployed workers are used to obtain a job. Employed workers, instead, do not use job offers for themselves but forward them to their unemployed contacts. This implies that the number of employed contacts determines the amount of information available to unemployed workers. Therefore, the higher the number of employed contacts, the higher their job-finding rate would be.

With wage bargaining between firms and workers, better connected workers will earn higher wages, conditional on employment, because the higher job offer arrival rate increases their reservation wage (e.g. Fontaine, 2008). However, if workers are heterogeneous in their skills, and jobs differ in the type of skills they require, mismatch may arise when employed contacts transmit opportunities about jobs which require different skills from the ones the unemployed possess (e.g. Bentolila et al., 2010). The degree of mismatch depends on the degree of homophily, which is the

\footnotetext{
${ }^{1}$ Studies in which networks transmit information about the productivity of workers through referrals to current employers, or can inform workers and firms about the quality of the match, include Saloner (1985), Montgomery (1991), Simon and Warner 1992, Mortensen and Vishwanath, 1994, and more recently, Brown et al. (2012), Dustmann et al. (2011) and Galenianos (2014). Referrals can also mitigate moral hazard problems through co-worker monitoring, allowing firms to pay lower efficiency wages (Kugler, 2003; Dhillon et al., 2013).
} 
tendency of individuals to befriend others who are similar to themselves. With a high degree of homophily, a better network quality is more likely to lead to better matches and higher wages. On the other hand, with a low level of homophily there will be more mismatch resulting in lower wages (Horvath, 2014).

Consistent with this framework, we offer the first empirical evidence - to the best of our knowledge - on the importance of the employment rate of friendship ties on the job finding rate and job match quality using longitudinal data. ${ }^{2}$ Previous empirical research on network effects in the labor market is based either on survey information on the use of informal search methods, such as friends and relatives, or on administrative records in which networks are defined indirectly using observable proxies, such as neighborhood, firm, or ethnicity. Studies on the use of informal search methods include Simon and Warner (1992), Pistaferri (1999), Marmaros and Sacerdote (2002), Loury (2006), Bentolila et al. (2010) and Pellizzari (2010). ${ }^{3}$ Studies defining networks indirectly using proxies include Topa (2001), Weinberg et al. (2004), Bayer et al. (2008), Hellerstein et al. (2011) and Schmutte (2015), who use geographic proximity at the neighborhood level; Cingano and Rosolia (2012), who define networks at the firm level; Edin et al. (2003), Munshi (2003) and Beaman (2012), who define networks based on immigrants’ ethnic origin; and Dustmann et al. (2011), who use information on both firms and ethnicity. ${ }^{4}$

The approach we propose in this study combines elements from these two strands of the literature for the definition of the relevant network and network quality. In particular, the relevant network is defined using survey information about friendship ties, while network quality is measured by the employment rate of those ties. That is, we do not rely on the use of informal search methods but on the quality of the network, and we do not assume that agents are connected within the

\footnotetext{
${ }^{2}$ Positive correlations between friends' employment and unemployment exits have been reported by Hannan (1999).

${ }^{3}$ As noted by Topa (2011), one limitation of studies using surveys on the usage of informal channels is that their analysis is based on those who are already employed, which can be a selected group among those who are searching for a job. In addition, workers who report that they found their current job through friends and relatives are those who have accepted the job opportunity offered through their informal contacts, and may have rejected other possible offers arriving from formal search channels (Montgomery, 1992). As we discuss in Section 4 we are taking into account this potential form of selection in our empirical framework.

${ }^{4}$ Wahba and Zenou (2005) consider the effect of network quality, which is proxied by the local unemployment rate or the number of family members in the labor force, on the probability of using friends and relatives for those employed, but they do not consider labor market outcomes.
} 
boundaries of the network proxy; rather, we directly observe network linkages through friendship ties. $^{5}$

One feature of our study is its focus on strong ties (close friends), while information on weaker social contacts is not available. This approach is common with a number of recent studies, using selfreported information on friends derived from survey questionnaires, where there is an upper bound on the total number of friends that can be reported (e.g. Calvó-Armengol et al. 2009; Conti et al. 2013). By observing only strong social ties it is not possible to consider whether weak ties matter more than strong ties, as discussed especially in sociology (see e.g. Granovetter, 1995). Indeed, if it is weak ties (or, more generally, additional contacts besides the ones on which we have information) that matter for finding a job and for match quality, then the approach taken in this paper based on strong ties would provide a lower bound to the network effect. In any case, the view that only weak ties are relevant is not consensual and has been challenged empirically. For example, Kramarz and Nordström Skans (2014) define networks at the family level and investigate the role of fathers on the employment and earnings of their children, finding that school graduates of lower ability are more likely to find a job through their parents, but with a wage penalty.

\section{Data and Sample Statistics}

We exploit longitudinal data on friendship ties and individual labor market outcomes from the British Household Panel Survey (BHPS) from 1992-2007. The BHPS is an annual representative survey of British households, which is running since 1991 and covers many aspects of life, including social ones. The longitudinal design of the BHPS allows observing each respondent's labor market outcomes over time, and, thence, yearly individual transitions across labor market states.

Information about social networks is gathered through a special questionnaire section on 'Social support networks', which was introduced in 1992 and administered at each even wave since then. Survey participants are asked to report information on their three closest friends, with friends'

\footnotetext{
${ }^{5}$ Holzer (1988) shows that there is a positive link between having more employed friends and searching for a job through friends; more employed friends lower the cost of using friends and relatives as a search method, which leads to a higher use of this search method. In our data, the method of job search is only available for a small part of the respondents, so we can only use the number of employed friends in the analysis.
} 
rankings chosen by the respondents. ${ }^{6}$ Each respondent provides information for each of the three friends. The section starts with questions about the demographic characteristics of the first friend (age, gender), followed by questions on residential proximity (four intervals in miles), friendship duration (years knowing the person in intervals), frequency of contact and type of relationship (relative vs. non-relative). The final question refers to the employment status of the friend. The same set of questions is then asked sequentially for the second and the third friend. Using the information on friends' employment status we can distinguish between employed and non-employed friends, which we use to measure network quality. We can, therefore, relate this friend-employment-based measure of network quality - observed at each even-numbered wave - to the respondent's employment transition between an even- and an odd-numbered wave.

We select a sample of respondents in all even waves during 1992-2006 who are 18 to 65 years old, not in full time education, and with non-missing information on employment status. We also restrict the sample to individuals with friends within the 18-65 age range in order to consider friends of working age. These selection criteria lead to a sample of 35,518 person-year observations. Of these, 7,213 are person-year observations in which the individual is non-employed. ${ }^{7}$ Employment includes full-time, part-time and self-employment, while non-employment includes unemployment based on the ILO definition and being out of the labor force (e.g. maternity leave, family care, or sick and disabled). We consider non-employment, rather than unemployment, for two reasons. First, if we only focus on the usual definition of unemployment - as those actively searching for a job in the last four weeks - we end up with a very small sample, which renders the main part of our analysis infeasible. Second, and most importantly, those who are currently out of the labor force may be discouraged workers who can still benefit from social networks. We return to this distinction at the beginning of Section 5 .

\footnotetext{
${ }^{6}$ Questions on friends are introduced by the following general statement: "Here are a few questions about your friends. Please choose the three people you consider to be your closest friends. They should not include people who live with you but they can include relatives." The set of questions is the same for each friend, with the exception of current occupation which is available only for the first friend.

${ }^{7}$ Information about all three friends is reported by the vast majority of respondents (92\%) and the analysis is based on these cases. The results reported in Section 5 are robust when including the few cases reporting less than three friends (adding dummies for missing friends in the set of controls). Restricting the sample of respondents to those aged 18-50 in order to avoid early retirement issues, or considering friends without an upper bound age, leads also to robust results compared to the ones presented in Section 5.
} 
Table A1 presents summary statistics of the sample. In the first five rows we report statistics about the employment status of respondents and their three reported friends. The full sample of 35,518 person-year observations corresponds to 9,395 individuals, out of which about 79 percent are observed in employment (28,305 person-year observations and 7,239 individuals). The remaining 7,213 person-year observations are in non-employment corresponding to 3,492 individuals. The average employment rate of each of the three respondents' friends is very similar (around 79 percent), with an average number of employed friends equal to 2.38. Focusing on person-year observations in the full sample, the average age of respondents is 39.11, and slightly more than half are women (53.2 percent). The demographic characteristics of all three friends are very similar to those of respondents' both in terms of age and gender. The age of friends is 39.4, 38.7 and 38.5 for the first, second, and third friend respectively, while the slightly younger second and third friends are more likely to be females compared to the first friend (54.7 percent of first friends are females vs. 56.9 percent of third friends). The remaining respondents' characteristics relate to education (highest qualification attained), family structure (couple, number of children), health (experiencing health problems, depression and being a smoker), and ethnicity (categorized in six groups). We also observe the region of residence (not reported) and the local unemployment rate defined at the travelto-work area (TTWA) level, which has a mean of 4.4 percent.

Finally, the average yearly job finding rate is 21.16 percent, which is increasing with the number of employed friends. While the transition rate is only about 10 percent for those with no employed friends, the job finding rate increases to about 16 percent with one employed friend, to 21 percent with two, and to almost 30 percent with three employed friends.

\section{Empirical Framework}

\subsection{Modeling Job Finding}

The empirical framework we propose is motivated by the theoretical literature which suggests that access to a better network of contacts implies a higher job finding rate. To identify the effect of network quality on job finding we model the transition probability from non-employment to employment $\left(p_{T}\right)$ as: 


$$
p_{T} \equiv \operatorname{Pr}\left(E_{i, t+1}=1 \mid E_{i, t}=0\right)=F\left(\alpha_{T}+X_{i, t}^{\prime} \beta_{T}+\delta_{T} Q_{i, t}+\eta_{T i}\right)
$$

where $E_{i, t}$ is a dummy indicator of respondent's $i$ employment status in year $t$, and $F($.$) is a function$ which is either linear or logistic. ${ }^{8}$ Equation (1) defines the probability of transitioning from nonemployment in year $t$ to employment in year $t+1$ as a function of network quality $\left(Q_{i, t}\right)$, a vector of other individual characteristics $\left(X_{i, t}\right)$ and individual unobserved heterogeneity $\left(\eta_{T i}\right)$. As we discussed in Section 3, the sample of non-employed respondents in year $t$ are observed during even waves because information on friends is only available during even-numbered waves (1992, 1994,..., 2006), and the transition is defined between even and odd waves (1992-1993, 1994-1995,..., 20062007).

The main identification issue we need to address is the potential endogeneity of network quality. Endogeneity may arise because friends are not randomly assigned, implying a correlation between network quality and the unobserved individual determinants of the employment transition: $\operatorname{cov}\left(Q_{i, t}, \eta_{T i}\right) \neq 0$. For example, individuals with a higher attachment to the labor market (higher values of $\eta_{T i}$ ) may exhibit a higher propensity to find a job and at the same time be connected to a higher quality network, which would lead to an upward biased network quality effect. Alternatively, friends may be exposed to similar local labor market shocks if they reside in similar areas (not necessarily in the same area), which would also induce spurious correlation between network quality and the transition into employment. Finally, the transition probability in equation (1) is conditioned on the sample of non-employed, which can be a selected sample; a form of initial conditions bias. To address these issues we consider three alternative estimation strategies: a fixed effects estimator, a semi-parametric correlated random effects estimator with initial conditions, and an instrumental variables (IV) estimator. All three estimation strategies can be derived from the more general model laid out in (1) by using different identifying assumptions, which we illustrate in Sections 4.2-4.4. We also control for local labor market conditions and provide additional evidence which suggests that our results are not driven by common shocks.

Identification of network effects is also complicated because of simultaneity, the so-called “reflection problem” (Manski, 1993). A large literature has developed in recent years focusing on the

\footnotetext{
${ }^{8}$ The logistic $F($.$) accounts for the limited dependent variable nature of the outcome, while with linear F($.$) the$ specification also includes a white noise error.
} 
identification of social interactions (see e.g. Manski, 1993, Moffitt, 2001, Bramoullé et al., 2009, and the comprehensive review by Blume et al., 2011). There are two features in our empirical setting which help dealing with the simultaneity problem. First, the longitudinal structure of the data allows focusing on the effect of the employment status of network connections (in year $t$ ) on the transition in year $t+1$. This time-sequencing argument is similar to the one used by Cingano and Rosolia (2012) and Schmutte (2015). Second, as shown by Blume et al. (2011), the non-linearity in models of limited dependent variables - like the one of equation (1) - may also break the reflection problem.

\subsection{Fixed Effects}

We now turn to the first strategy of estimating the effect of network quality in equation (1) based on a fixed effects estimator (either linear or logistic). We pool data on non-employment observations from 3,492 respondents across all even waves and exploit the fact that we observe about 50 percent of them in non-employment for more than one wave (1,759 individuals). This provides withinindividual variation in network quality over time and across individual non-employment observations, which we use to eliminate time-invariant unobserved heterogeneity $\left(\eta_{T i}\right)$ that might be correlated with network quality (within estimator). Network quality is defined by aggregating over the employment status of the three friends. That is, $Q_{i, t} \equiv N E F_{i, t}$, where $N E F_{i, t}$ denotes the number of employed friends in year $t$ for individual $i$, which varies from zero to three.

Because fixed effects rely on observing individuals as non-employed in more than one even wave, we expect the fixed effects estimates to provide a lower bound of the network effect. This is because the individuals contributing in the estimation are likely to be negatively selected in the sense of being less employable and, therefore, experiencing a lower transition into employment. We also use a fixed effects logit estimator which requires a transition into employment in at least one of the multiple non-employment person-year observations. For this estimator we exploit 1,604 person-year observations out of 501 individuals.

The fixed effect estimator can be biased if network quality is not strictly exogenous and depends on past values of the dependent variable. For instance, individuals who remain nonemployed might be more likely to select new friends who are also non-employed. We present descriptive evidence in Table 1 (Panels A and B) which suggests that respondents do not form links 
with new friends based on whether these new friends are employed or not. We compare the average number of employed friends between respondents reporting at least one new friend (Column 2), and no new friend (Column 3). ${ }^{9}$ The difference in the average number of employed friends between the two groups (with, or without new friends), reported in Column 4, is very small and it is not statistically different from zero, both for the full sample (Panel A) and for the sample of nonemployed (Panel B). This should not be surprising because it is reasonable to expect that close friendships are not solely determined by economic considerations. This evidence is consistent with strict exogeneity of network quality, although it does not rule out the possibility that past shocks to individual employment trajectories affect future levels of network quality. For this reason, later in the Section we introduce an instrumental variable estimator which exploits exogenous variation in friends' employment status to addresses endogeneity of network quality due to all possible sources, including the one operating through past values of the dependent variable.

\subsection{Semi-Parametric Random Effects}

Unrelated to the way in which endogeneity due to unobserved heterogeneity is addressed, the other form of potential bias when estimating equation (1) is related to conditioning on the sample of nonemployed $\left(E_{i t}=0\right)$. As we discussed in Section 4.1, being non-employed can be endogenous in the presence of serial correlation of the employment process, which is an issue of initial conditions (Heckman, 1981). To deal both with the endogenous selection in non-employment and unobserved heterogeneity we propose an alternative estimation strategy. This second strategy relies on a random effects estimator, which augments the transition equation with the explicit modeling of the probability of being non-employed at time $t$ in order to account for endogenous selection in nonemployment. Therefore, with this estimator we do not restrict the sample to the non-employed respondents, but instead we consider the full sample of employed and non-employed observations (35,518 person-year observations and 9,395 individuals). We model selection into non-employment via the following initial condition equation:

\footnotetext{
${ }^{9}$ Each respondent answers the following question for each of the three friends: "About how long have you know him or her?" with possible answers "Less than 1 year ”, "1-2 years”, “3-10 years”, "10 years or more”. A friend is defined as "new" if he or she is known for less than 1 year.
} 


$$
p_{N} \equiv \operatorname{Pr}\left(E_{i, t}=0\right)=F\left(\alpha_{N}+X_{i, t}^{\prime} \beta_{N}+\delta_{N} N E F_{i, t}+\theta_{N} u_{i, t-1}+\eta_{N i}\right),
$$

which defines the individual probability of being non-employed in year $t$. The lagged unemployment rate in the travel to work area $\left(u_{i, t-1}\right)$ is included to proxy the accumulation of past unemployment shocks that may affect employment status prior to the transition.

Similar to the fixed effects estimator we assume time-invariant unobserved heterogeneity influencing selection into non-employment, denoted by the term $\eta_{N i}$. However, rather than eliminating it by applying within-individual differencing, we tackle endogeneity by modeling the association of unobserved heterogeneity with network quality via a correlated random effects specification (see Mundlak, 1978; Chamberlain 1984). The specification of unobserved heterogeneity affecting the transition equation (1) and the selection equation (2) is the following:

$$
\begin{gathered}
\eta_{T i}=\bar{X}_{i}^{\prime} \lambda_{T}+\omega_{T i} \\
\eta_{N i}=\bar{X}_{i}^{\prime} \lambda_{N}+\omega_{N i} .
\end{gathered}
$$

The vector $\bar{X}_{i}$ collects the individual averages of time varying regressors, including network quality measured by the number of employed friends (NEF). They are computed across all panel waves so they are constant across transitions. After controlling for time averages (especially the mean number of employed friends), the remaining unobservables are assumed to be orthogonal to the current measure of network quality: $\operatorname{cov}\left(N E F_{i, t}, \omega_{T i}\right)=0$ and $\operatorname{cov}\left(N E F_{i, t}, \omega_{N i}\right)=0$.

We estimate the transition equation (1) jointly with the selection equation (2) by maximum likelihood allowing for correlated unobserved heterogeneity across the two equations. One concern with this model might be that identification of the cross-equation correlation of unobservables is mainly driven by the functional form of the model. However, as discussed by Mroz and Savage (2006), this is more serious if the model includes only time-invariant variables. Exogenously timevarying regressors, like the local unemployment rate, provide a more robust source of identification. Identification is also enhanced by the variation coming from repeated individual non-employment which we observe in the data. Another possible concern could be that the employment probability of the respondent (the dependent variable in equation 2) is observed contemporaneously with network quality (the number of employed friends). This can generate a correlation between NEF and the individual error term $\omega_{N i}$ because the employment probability of the respondent may affect the 
number of employed friends (a form of "reverse causality" in the initial conditions equation). As a sensitivity analysis, we also estimate the model excluding the current number of employed friends and its time average and we obtain very similar results. We discuss this sensitivity analysis in Section 5.2.

Furthermore, we impose relatively mild assumptions on unobserved heterogeneity, which is modeled in a flexible way assuming a discrete distribution, following Heckman and Singer (1984). More specifically, the unobserved heterogeneity is defined as a discrete distribution with the support points denoted by $\left(\omega_{T m}, \omega_{N m}\right)$ and the corresponding probability mass given by $\operatorname{Pr}\left(\omega_{T i}=\omega_{T m}, \omega_{N i}\right.$ $\left.=\omega_{N m}\right)=\pi_{m}$. Each unobserved factor is assumed to be time-invariant and individual specific for each outcome and the sample likelihood is given by

$$
L=\prod_{i=1}^{N} \sum_{m=1}^{M} \pi_{m} l_{i m}
$$

The individual likelihood contribution denoted by $l_{\text {im }}$, given the observed and unobserved characteristics, is defined as:

$$
l_{i m}\left(Z_{i}, \omega_{T i}, \omega_{N i}\right)=\left(p_{T m}\right)^{\tau_{T}}\left(1-p_{T m}\right)^{\left(1-\tau_{T}\right)}\left(p_{N m}\right)^{\tau_{N}}\left(1-p_{N m}\right)^{\left(1-\tau_{N}\right)},
$$

where $p_{T m}$ and $p_{N m}$ denote probabilities evaluated at the mass points, $\tau_{T}$ is a dummy for $E_{i, t+1}=1$ in the sample with $E_{i, t}=0, \tau_{N}$ is a dummy for $E_{i, t}=0$, and $Z_{i}$ includes the controls of equations (1) and (2) plus the individual averages of time-varying regressors. Since the specification for each equation includes a constant, for identification one mass point of each unobserved factor is normalized to zero. The function $F$ in equations (1) and (2) is assumed to be logistic.

\subsection{Symmetric Network - Instrumental Variables}

The third identification strategy addresses endogeneity of network quality by way of an instrumental variables estimator (IV), which does not impose the assumption of time-invariant unobserved heterogeneity. The important assumption with the IV estimator is the existence of a valid instrument, i.e. a source of exogenous variation in network quality as measured by the employment status of the respondent's friends. It is difficult to uncover such a variable in the BHPS because of the limited information on friends' characteristics. To circumvent this data limitation, we consider the transition equation (1) from the friends' perspective and estimate its symmetric version. That is, instead of 
estimating the effect of network quality on the respondent's transition, the symmetric transition focuses on the effect of the employment status of the respondent on the employment transition of the respondents' friend. ${ }^{10}$

Strictly speaking, estimating this symmetric transition requires observing friends' identity in order to follow their employment status over time, but friends' identity is not available in the data. We therefore base the analysis on the first closest friend assuming that his or her identity is the same over the transition period. ${ }^{11}$ In this symmetric version, network quality is measured by the employment status of the BHPS respondents: $Q_{i, t} \equiv E_{i, t}$. Let $F E_{i, t}$ be a dummy for whether the first friend is employed in year $t$, the symmetric transition equation is defined as:

$$
p_{T F} \equiv \operatorname{Pr}\left(F E_{i, t+2}=1 \mid F E_{i, t}=0\right)=F\left(\alpha_{T F}+X_{i, t}^{\prime} \beta_{T F}+\delta_{T F} E_{i, t}+\eta_{T F i}\right) .
$$

Equation (5) is similar to transition equation (1) but it refers to the transition from nonemployment to employment of the first friend, and therefore, is estimated on the sample of respondents whose first friend is non-employed at time $t\left(F E_{i, t}=0\right)$. The dependent variable is a dummy which takes the value one if the respondent's first friend makes a transition from nonemployment in year $t$ to employment in year $t+2$, and zero otherwise. We consider a 2-year transition because the information on friends in the survey is only available every two years. ${ }^{12}$

The vector $X$ includes all available friend characteristics (age, gender), and the respondents' characteristics such as education, family structure, health status, experiencing depression, smoking and region of residence, which are included in the specification as proxies for the unobserved characteristics of the friend. By relying on proxies, we can only imperfectly control for the characteristics of the friend, especially when those characteristics are very different between the respondent and the friend. We also do not observe the employment status of other friends of the respondent's friend, so network quality is defined only by the employment status of the respondent. This could induce omitted variable bias, a caveat to keep in mind when interpreting the results of the

\footnotetext{
${ }^{10}$ We thank Nikos Askitas for his suggestion to consider the symmetric model.

11 The plausibility of this assumption is assessed in Section 5.3 by investigating the sensitivity of the results for a fixed network of friends. We find the results to be robust to the assumption of constant identity of the first friend. Another assumption implicit in the symmetric model is that of reciprocity, i.e. that the first friend of the respondent also considers the respondent as his or her friend.

12 The drawback of considering a 2-year transition is that we may miss shorter transitions to employment which are not long-lasting. In that case, our findings are expected to be downward biased as we would be ignoring these transitions in the definition of the dependent variable.
} 
symmetric transition.

Despite these limitations, the main advantage of the symmetric transition is that we can construct an instrument for the potentially endogenous network quality - measured by employment status $\left(E_{i, t}\right)$ - by exploiting the abundance of information about the respondents in the BHPS. We use two sources of information to construct the instrument. The first is whether the respondent experiences health problems. The second is the answer to the following question: "Does your health limit the type of work or the amount of work you can do?” The instrument for the potentially endogenous employment status of the respondent is the onset of a health problem between the previous and the current interview, which limits the work activities of the respondent. The instrument, which is denoted by $W L_{i, t}$, is a dummy taking the value one for the respondents who experienced the onset of health related work limitations between year $t-1$ and year $t$, and zero otherwise. The instrumenting equation determining the endogenous employment status of the respondent is given by:

$$
p_{E} \equiv \operatorname{Pr}\left(E_{i, t}=1\right)=F\left(\alpha_{E}+X_{i, t}^{\prime} \beta_{E}+\theta_{E} W L_{i, t}+\eta_{E i}\right)
$$

The onset of a health related work limitation between year $t-1$ and $t$ is expected to have a negative effect on the probability of the respondent to be employed in the current period. The identifying assumption that the instrument is exogenous, i.e. $\operatorname{cov}\left(W L_{i, t}, \eta_{T F i}\right)=0$, implies that the onset of a health related work limitation for the respondent in the past period has no direct effect on the employment transition of the first friend in the current period. The identifying assumption of this estimator would be violated in the presence of correlation between the health status of the respondent and that of the first friend. In that case, the unobserved health status of the first friend would be correlated with the instrument (the onset of health limitations for the respondent). We address this issue by including indicators for the current (in year $t$ ) level of respondent's health among the regressors in the transition equation. By controlling for the current health status we are able to capture the potential correlation in health between the respondent and the first friend. ${ }^{13}$

\footnotetext{
${ }^{13}$ Individuals taking time out of job search activities to help their friends hit by health shocks may induce violation of the exclusion restriction. While possible in principle, we do not consider such mechanism harmful in practice for our estimates: the most relevant source of help for individuals experiencing illness is represented by spouses who are not counted as friends in the BHPS as long as they co-reside with the respondent. Excluding relatives (the other likely source of helping the ill) from the friends' count did not alter the substance of our main findings.
} 
Finally, due to the limited dependent variable nature of both the dependent variable and the instrumented variable, equations (5) and (6) are estimated jointly by maximum likelihood allowing for unrestricted correlation between the unobserved characteristics $\left(\eta_{T F i}, \eta_{E i}\right)$ using a discrete distribution. The construction of the likelihood is similar to the one for the random effects estimator presented above. We also estimate the model assuming linearity, which provides robust results (discussed in Section 5.3).

\section{Results - Transition into Employment}

In this section, we discuss the results for the effect of network quality on the transition into employment for the three empirical approaches: the fixed effects estimator (in Section 5.1), the semiparametric random effects estimator (in Section 5.2) and the symmetric IV estimator (in Section 5.3).

We start by presenting estimates from a simple pooled linear regression of transition equation (1) ignoring both unobserved heterogeneity and selection into non-employment. The coefficient of the number of employed friends, reported in the first column of Table 2 (Panel A), has a value of 0.04 and it is statistically significant. This suggests that one additional employed friend increases the job finding probability by 4 percentage points (p.p.). We also estimate the transition equation allowing for a flexible specification of network quality with dummies for the number of friends employed, i.e. having one, two, or three employed friends, relative to having no employed friends. The coefficients of the dummy specification, reported in the second column of Panel A, suggest a non-linear relationship. Having one employed friend increases the job finding probability by 1.6 p.p., but the coefficient estimate is not statistically different from zero, whereas two or three employed friends are associated with a 4.9 p.p. and 11.1 p.p. increase in the job finding probability, respectively, which are both statistically significant.

The baseline result is also significant (at the 1 percent significance level) when we estimate separately the employment transition for the unemployed and those out of the labor force. The coefficient estimate for the sample of unemployed is higher compared to the estimate for the sample of those who are out of labor force (0.048 vs. 0.035 - not reported). As we discussed in Section 3, in what follows we will focus on the sample of non-employed, which includes both groups. 


\subsection{Fixed Effects Estimates}

\subsubsection{Baseline Results}

The pooled linear regression estimates just shown are likely to be upward biased because of potential endogeneity of network quality due to non-random assignment of friendship ties. Following the discussion of Section 4.1, the first strategy we use to address the potential endogeneity driven by unobserved heterogeneity is based on estimating the transition equation (1) with fixed effects. Once we control for individual time-invariant unobserved heterogeneity, the coefficient of the number of employed friends in the linear fixed effects estimation is reduced to 0.018 , but it remains statistically significant. This estimate, reported in third column of Table 2 (Panel A), suggests an increase of 1.8 p.p. in the transition probability for an additional employed friend. Identification in the linear fixed effects estimator relies on individuals who are observed with at least two non-employment personyear observations (1,759 individuals out of 3,492 non-employment observations). As this group is likely to be less employable, it is not surprising that the linear fixed effects estimate is much smaller than the one obtained from the pooled linear regression in Table 2. ${ }^{14}$

We also estimate the linear fixed effects model by allowing for a flexible specification of network quality, and we report the coefficient estimates in the fourth column of Panel A. Similarly with the pooled linear regression results, we find that having two or three employed friends (relative to none) has a positive and significant effect on the probability of becoming employed. The higher the number of employed friends the higher is the increase in the transition probability, but the effect of an additional friend from the fixed effects estimates does not follow the clear non-monotonic pattern we obtained from the pooled linear regression.

\subsubsection{Sensitivity Analyses}

The baseline fixed effects estimates suggest that having more employed contacts increases the chances of finding a job even after controlling for individual time-invariant unobserved heterogeneity. We perform a series of sensitivity checks with the fixed effects estimator, which we present in Panel B of Table 2.

\footnotetext{
${ }^{14}$ Indeed, the coefficient estimate from a pooled linear regression on the sample of individuals who contribute to the linear fixed effects estimation is 0.024 (not reported in Table 2), which is substantially lower compared to the one from the full sample (0.040 from Column 1, Panel A).
} 
First, we allow for a differential effect of network quality among new friends, which allows separating the effect of network quality of a fixed network from a potentially endogenously changing network quality. We define as "new" those friends with a length of friendship of less than a year. We find that the interaction of the number of employed friends with an indicator of having any new friends has no effect on the transition probability (Column 1, Panel B).

Second, we estimate the transition equation with a conditional logit fixed effects estimator. The coefficient estimate of the number of employed friends from this conditional logit fixed effects, reported in the second column of Panel B, is also positive and statistically significant. The marginal effect is equal to 0.035 , which falls between the pooled and the linear fixed effects estimates. ${ }^{15}$ The sample contributing to the estimation in the conditional fixed effect logit is a much smaller group of individuals (in total 501 non-employed respondents), who are expected to be the least negatively selected among those with multiple non-employment observations because they all become employed at least once. Therefore, we would expect for that group a higher overall effect. This is indeed what we observe when we estimate a pooled linear regression using only the observations contributing to the logit fixed effects estimator. We obtain a coefficient estimate of 0.043 against an estimate of 0.024 when we use the sample which contributes to the linear fixed effects regression (see footnote 14) and an estimate of 0.040 from the full sample.

Third, we checked the sensitivity of the baseline results to the inclusion of additional controls. In particular, we included a full set of interactions of time-varying individual and friend characteristics with the gender dummy to capture unobserved heterogeneity in the data that varies over time and might be correlated with network quality. We also included a full set of dummies of the industry in the last employment. In both cases the main effect is not sensitive to the inclusion of these additional controls; results from these sensitivity checks are not reported and are available upon request.

\subsubsection{Correlated Shocks}

A remaining concern about these baseline results is the presence of correlated shocks. Network

\footnotetext{
15 The marginal effect for the fixed effect logit is computed as $\delta_{T} p(1-p)$, where $\delta_{T}$ is the estimated coefficient on the number of employed friends, while $p$ is the average sample predicted probability.
} 
formation may occur through residential proximity; therefore, spatial correlation is an obvious source of correlated shocks. For example, a plant closure at the local area is a common shock that might affect the conditions for all members of the network. We consider the importance of local economic conditions for our findings in three ways.

First, we find that the fixed effects estimates are not sensitive to the exclusion of the travel-towork area unemployment rate (results of this sensitivity check are not reported and are available upon request). Second, we investigate the extent to which the effect of network quality varies by the frequency of contact and residential location of friends. Table A2 in the Appendix shows that only the strength of friendship (contact frequency) and not the location of friends (residential proximity) matters for the job finding probability. In Panel A of Table A2, we present the coefficient estimates of two different regressions; one for contact frequency and the other for residential proximity. The estimates for the number of employed friends with strong ties (frequency of contact at least once a week) and the number of employed friends who live close (less than 50 miles) are positive and statistically significant (coefficients of 0.023 and 0.020, respectively). In Panel B, we present the estimates from a single regression in which we consider the effect of network quality jointly by contact frequency and residential proximity. These results suggest that the location of friends is not a driving factor for our findings; the estimate for the number of employed friends who are strong ties is significant for both friends who reside in close distance and further away. In contrast, the effect of network quality among friends who do not interact frequently is insignificant for both friends who live close and for those who live far from the respondent. That is, stronger ties among close friends increase job finding rates irrespective of their location.

We also find that the effect of strong and far-living ties is related to residential mobility of the respondent. In Panel C we report the estimates of a similar regression to the one presented in Panel B but with the dependent variable defined as the probability of entering employment combined with a residential move over the transition period. We find that individuals with more employed strong and far-living ties are significantly more likely to become employed and also move residentially. Farliving weak ties also increase the probability to move with a new job, but the effect is not statistically significant. In contrast, close-living ties (either strong or weak) have no effect on the probability of getting a job which is combined with residential mobility. These results provide additional evidence 
that the positive effect of strong ties on job finding when residing far away from the respondent is related to the transmission of job opportunities, since job finding is combined with residential mobility.

Third, we check whether the employment status of friends predicts the probability of job loss. We can identify job loss in the BHPS using information on the reason for stopping the previous job, and in particular, whether the respondent was 'made redundant' or 'dismissed or sacked'. We consider the sample of individuals who are employed in period $t$ and we estimate a linear fixed effect model for the probability of losing the job in period $t+1$. If our model succeeds in eliminating correlated shocks, then we should expect no effect of the number of employed friends on such 'reverse' transition. The coefficient estimate, reported in the third column of Table 2 (Panel B), is essentially equal to zero. Both the finding of an effect through contact strength (and not through residential proximity), and the lack of any effect on the job loss transition, provide evidence which suggests that the effect of network quality on job finding rates is not driven by correlated shocks. ${ }^{16}$

\subsection{Semi-Parametric Random Effects Estimates}

We turn to the results from the second estimation strategy for identifying the effect of network quality by way of the semi-parametric random effects estimator presented in Section 4.3, which allows for unobserved heterogeneity and takes into account selection in the initial state of nonemployment. The effect of the number of employed friends on the transition into employment is positive and significant (coef. 0.252, se. 0.063 ) and the corresponding marginal effect is equal to 3.1 percentage points. These results are reported in the fifth column of Table 2 (Panel A). The magnitude of this effect lies between the one obtained from the simple pooled linear model, which ignores both unobserved heterogeneity and the initial condition (4 p.p.), and the fixed effects model, which controls for unobserved heterogeneity but ignores selection into non-employment (1.8 p.p.).

\footnotetext{
${ }^{16}$ A related issue is that of continuing spells. The fixed effects model relies on observing individuals in non-employment more than once, and some of these observations may belong to the same spell of non-employment. If respondents and their friends participate in the same job search process, they will start and end non-employment spells at the same time, inducing spurious correlation between network quality and respondents' job finding. Estimating the model excluding data from continuing spells, however, produced a coefficient for network quality of 0.065 , though imprecisely estimated due to small cells (t-ratio = 1.03). Estimates from this sample rely only on variation of network quality between employment spells, suggesting that our main results are unlikely to be driven by spurious correlation due to continuing spells.
} 
Considering together these effects, we find robust evidence that network quality has a positive and significant effect on job finding rates. Our preferred estimate from the correlated random effects model, which controls for selection in non-employment, suggests that an additional employed friend increases the job finding probability by as much as 15 percent (marginal effect of 3.1 p.p. and unconditional exit rate of 21.16 percent). We also report the estimates from the dummy specification in the sixth column of Panel A. As with the pooled OLS and the linear fixed effects estimates, the effect is increasing with the number of employed friends and it is significant for those with two or three employed friends. We also note that the network quality effect in the correlated random effect estimation preserves the non-linearity we observed in the raw data and in the pooled OLS regressions.

To form a comparison with the results from fixed effects, we also estimated the correlated random effects model ignoring selection into non-employment. The fourth column in Panel B (Table 2) shows that the coefficient estimate for the number of employed friends is positive and statistically significant (coef. 0.155, s.e. 0.061). The marginal effect suggests that an additional employed friend increases the transition probability into employment by 1.8 percentage points. This effect is similar in magnitude to the one obtained with fixed effects, which also does not take into account selection into non-employment.

Finally, as we discussed in Section 4.3, the number of employed friends in the initial condition equation is observed in the same time period with employment status, which may lead to simultaneity bias. As a sensitivity analysis, we have estimated the model excluding the current number of employed friends and its time average from the initial condition equation. The estimated coefficient for the effect of the number of employed friends on job finding probability changes from 0.252 (s.e. 0.063 ) to 0.235 (s.e. 0.062). We conclude that our main findings from the correlated random effects model with initial conditions are robust to this potential concern.

\subsection{Symmetric Network Instrumental Variable Estimates}

The third approach for estimating the effect of network quality on the transition into employment is based on the symmetric model, where the transition is defined on the sample of respondents whose first friend is non-employed in year $t$. The network quality effect is captured by the employment 
status of the respondent, which is potentially endogenous. We address this endogeneity by using the onset of health related work limitations as an instrument, which can create exogenous variation of network quality (see the discussion in Section 4.4). Relative to the two previous approaches, the IV estimator deals with endogeneity due to all types of unobserved heterogeneity, not only timeinvariant ones, and with potentially endogenous network formation driven by past outcomes.

Table 3 displays the results from estimating the symmetric transition equation (5) for the sample of non-employed first friends. We start by discussing the results without instrumenting for the endogenous employment status of the respondent. The estimation in the first column of Table 3 (Panel A) is based on a linear regression and shows a positive and statistically significant effect of the respondent's employment status on the employment transition of the first friend. The estimated coefficient suggests a 9.2 p.p. increase in the transition probability of having an employed contact (referring to the respondent, which is denoted as "Respondent Employed" in the table) compared to having a non-employed contact. ${ }^{17}$ In the second column of Panel A, we report the results of estimating the symmetric transition equation with fixed effects, similar to the analysis for the direct model of equation (1) discussed in Section 4.1. The effect of the respondent's employment status is reduced from 0.092 to 0.065 , but it is still statistically significant at the 5 percent confidence level.

We now turn to the IV results of Table 3 in Panel B where we present two different estimations based on different specifications. We start by discussing the baseline estimates reported in the first column. The coefficient estimate of the instrumental variable indicates that the instrument operates in the expected direction. The onset of health related work limitations between year $t-1$ and year $t$ reduces the employment probability of the respondent in year $t$, with the coefficient estimate being statistically significant at the 1 percent confidence level (t-ratio: 3.72). Considering the estimate of the main effect of interest in the transition equation, we find a positive and statistically significant network effect (coef. 0.393, s.e. 0.094). In terms of marginal effect, an employed respondent increases by 7.5 p.p. the transition probability from non-employment to employment of the first

\footnotetext{
${ }^{17}$ A direct comparison with the marginal effects from the fixed effects and the semi-parametric random effects estimates cannot be made because the transition in the symmetric model is defined over the $(t, t+2)$ interval, rather than $(t, t+$ 1) as in the fixed or random effects, and the variable of interest is a dummy for the employment status of the respondent rather than the respondents' number of employed friends.
} 
friend. This marginal effect lies between the marginal effects from the linear fixed effects (6.5 p.p.) and the linear pooled estimation (9.2 p.p.), which are reported in Panel A. ${ }^{18}$

In the second column of Panel B, we report the results from another specification in which we include the current health and depression indicators of the respondent. If the onset of a health limitation by the respondent is due to a common shock that is also affecting the health status of the friend, this would violate the identification assumption of the IV estimator. By controlling for the current (in year $t$ ) health indicators of the respondent (on top of the onset of a health limitation between $t-1$ and $t$ ), we attempt to control for this potential correlation and check the robustness of our IV results. Since the current health and depression indicators are correlated with the onset of health limitations in the last year, we expect that including them in the specification will lead to a weaker instrument. This is what we observe from the coefficient and the marginal effect of the instrument, reported in the second column of Panel B, which is smaller in absolute terms and the level of significance is reduced. What is important, however, is that the main effect of interest remains practically unchanged as the effect of the respondent being employed changes only slightly from a marginal effect of 0.075 to $0.073 .^{19}$

As we discussed in Section 4.4, the estimation of the symmetric model relies on assuming the identity of the first friend remains constant between subsequent even waves. We investigate the sensitivity of our results to this assumption by restricting the sample to non-employed first friends who remain fixed between years $t$ and $t+2$. We perform this sensitivity check for two subsamples. The first is the sample restricted to respondents who do not have a new first friend in the next wave in which they report information about their close friends. A friend is defined as "new" if the length of friendship is less than 2 years (the distance between the two waves with information on friends). The second is the sample restricted to respondents who report a first friend in the next wave of the same gender as in the current wave, and of age which is logically consistent two years later. We report the results from these two sensitivity checks in Table A3, which confirm that the main

\footnotetext{
18 The coefficient estimate from a linear IV estimation is equal to 0.082 (or a 8.2 p.p. increase in the transition probability), which is significant at the 1 percent confidence level (s.e 0.007).

${ }^{19}$ We also performed the estimation excluding each indicator - health or depression - in turn, reaching identical conclusions to those reported in the text. In addition, we have considered accidents as a potentially alternative way to model the onset of health related work limitation. However, the frequency of accidents in our sample is small so we could not pursue this further.
} 
findings are not sensitive to the constant identity assumption of the first friend. Both in the sample without a new first friend (Panel A), and in the sample of friends with the same demographic characteristics (Panel B), we find a positive and statistically significant network effect. When the respondent is employed, the transition from non-employment to employment of the first friend increases. Similar findings are obtained when we consider only long friendships, which are not reported but are available from the authors. Overall, the IV estimates provide robust evidence of the existence of a network effect, which is consistent with the evidence obtained both from the fixed effects and the semi-parametric correlated random effects estimators.

\section{Match Quality}

In this section, we extend the analysis to the effect of network quality on the quality of the matches formed by those who found a job, measuring match quality using labor market outcomes such as wages and employment stability. As discussed in Section 2, better connected workers will increase their reservation wage and earn higher wages because of increased bargaining power. If informal networks lead to better matches who pay higher wages, this should result in lower separation rates (Dustmann et al., 2011), and thus to higher employment stability. However, mismatch may arise when there is a low degree of homophily among social ties, and employed contacts transmit opportunities about jobs which require different skills from the ones the unemployed possess. This mismatch may lead to lower wages and lower employment stability. The empirical literature so far has produced mixed results. Some studies find positive network effects on wages (e.g. Simon and Warner, 1992; Marmaros and Sacerdote, 2002; Loury, 2006), while others find negative effects (e.g. Pistaferri, 1999; Bentolila et al., 2010).

The analysis for the effects of network quality on wages and employment stability is conducted by extending the correlated random effect estimator of Section 4.3 to outcomes occurring after the transition into employment. Small cell size and unavailability of wages for the first friend prevent us to use fixed effects and IV estimators, respectively, in this context.

\subsection{Wages}

Given the longitudinal nature of the data, we can follow individuals over time and investigate the 
effect of network quality on wages for those who find a job. The (log) wage equation is given by:

$$
\log \left(W_{i, t+1}\right)=\alpha_{W}+X_{i, t+1}^{\prime} \beta_{W}+\delta_{W} N E F_{i, t}+\eta_{W i}+\varepsilon_{i, t+1}, \quad \text { if } E_{i, t+1}=1 \text { and } E_{i, t}=0
$$

where the dependent variable $W_{i, t+1}$ denotes the hourly wage and the independent variables are measured in year $t+1$. The specification includes $\eta_{W i}$, which captures the effect of unobserved heterogeneity on wages, and a white noise error. Network quality is measured by the number of employed friends (NEF) in year $t$; the year before the transition in which the worker was nonemployed.

The coefficient estimate of network quality in equation (7) from a simple linear regression, reported in the first column of Table 4 (Panel A), is equal to 0.034 and it is statistically significant. While this result suggests a positive network quality effect on wages one has to view it with caution; those who find a job are likely to be selected among the non-employed because they may possess unobserved traits which render them more likely to become employed and also receive higher wages. To address this selection due to unobservables, we estimate the wage equation (7) jointly with the non-employment transition (1) and the initial condition equation (2) (defined in Sections 4.1 and 4.3, respectively), taking into account the correlation of unobserved heterogeneity across the three outcomes. By jointly estimating the probability of entering employment and the realized outcome (wages), we are able to separate the effect of interest from selection based both on observable and unobservable characteristics. The coefficient estimate of the number of employed friends from the correlated random effects model, presented in first column of Panel B (Table 4), is equal to 0.017 and it is not statistically significant. This suggests that the linear regression estimate (0.034) is upward biased because of correlation of unobserved heterogeneity among network members.

\subsection{Wages - Heterogeneity by Skill Level and Type of Relationship}

We have argued that the matching effect of network quality varies by homophily of social contacts; to investigate whether this is the case, we extend further the analysis allowing for heterogeneity by skill level of the respondents, and by the type of relationship between the respondents and their social contacts. We distinguish between high- and low-skilled respondents, and between contacts 
who are friends or relatives. ${ }^{20}$ While we do not observe the skill level of the reported friends, we expect a higher degree of homophily between skilled respondents and their networks of friends rather than their networks of relatives — because skilled respondents are more likely to befriend with similar individuals.

That high-skilled friends, rather than relatives, are more similar to each other is confirmed in the BHPS data by considering two dimensions of homophily; occupation and age. Focusing on the sample of employed respondents and employed first friends, for whom we observe current occupation, we find that friends and high-skilled respondents are significantly more likely to be in the same occupation compared to relatives and low-skilled respondents. We obtain these results by regressing an indicator of being in the same occupation on a high-skilled dummy, and on a dummy for the first reported friend being a friend rather than a relative. We also obtain positive and statistically significant estimates for the friend and the skilled dummies when we consider as the dependent variable whether the respondents and their first friends are of the same age. That is, in both dimensions we find higher homophily between high-skilled respondents and friends rather than between low-skilled respondents and relatives. ${ }^{21}$

Due to homophily between skilled friends, we expect the quality of friends' networks of highskilled respondents to increase the matching quality of jobs, leading to higher wages. In contrast, due to low degree of homophily, and in particular occupational mismatch between low-skilled and relatives, we expect the quality of relatives' networks of low-skilled respondents to reduce the matching quality of jobs, leading to lower wages (e.g. Bentolila et al., 2010).

Both the results from a simple linear regression of equation (7), reported in Panel A of Table 4, and from the correlated random effects model that accounts for the transition into employment, reported in Panel B of Table 4, show that better network quality leads to higher wages for highskilled workers, and in particular for high-skilled workers with a higher number of employed friends who are non-relatives. The simple linear regression coefficient estimate of the number of employed

\footnotetext{
${ }^{20}$ High skilled are defined as those respondents with A-levels and higher education. Each respondent is also asked if a reported friend is a relative or not. Reporting a relative or a non-relative among the three close friends is not related to the quality of the network. Indeed, for the sample of non- employed respondents there is no difference in the mean number of employed friends between those who ever report a relative as a friend and those who never report a relative among their friends.

${ }^{21}$ The sample for the age regression is based on all respondents, both employed and non-employed. Both regressions include a female dummy and year fixed effects. These results are available upon request.
} 
friends for high-skilled workers is equal to 0.047 (Column 2, Panel A), while the random effects estimate is equal to 0.044 (Column 2, Panel B), where both are positive and significant. Distinguishing between network quality among relatives and non-relatives, the linear regression coefficient of the number of employed non-relatives for high-skilled workers is equal to 0.064 (Column 4, Panel A) and the random effects estimate is equal to 0.061 (Column 4, Panel B), where both are again positive and significant. The coefficient estimate of 0.061 implies that an additional non-relative employed friend for high skilled individuals leads to a 6.1 percent increase in hourly wages.

While for high-skilled respondents the estimate of network quality changes only slightly between the simple linear regression and the random effects model (from 0.064 to 0.061 ), for lowskilled respondents we observe a stronger upward bias in the linear regression results. In particular, the coefficient estimate in the linear regression which is equal to 0.021 (Column 2, Panel A) reduces to -0.012 in the random effects model (Column 2, Panel B). We also observe a similar reduction between the linear regression and the random effects estimates for the specification in which we distinguish between relative and non-relative contacts (Column 4). The fact that the variation is more pronounced for the low-skilled is likely to be driven by a stronger correlation of unobserved heterogeneity among low-skilled network members. Overall, for low-skilled individuals we find that a higher number of employed friends, and in particular relatives, leads to a wage penalty (coefficient of -0.043 in the fourth column of Panel B) although the effect is not statistically significant. ${ }^{22}$

These findings are consistent with previous evidence on positive wage effects for high-skilled workers, who find a job through friends, and negative wage effects for low-skilled workers who find a job through relatives. For example, Simon and Warner (1992) find that hiring through contacts for a sample of high-qualified workers leads to a higher initial wage, while Kramarz and Nordström Skans (2014) find that school graduates of lower ability are more likely to work in the firm in which their father is employed, but with a wage penalty. Overall, these results help reconcile the mixed evidence of the previous literature on searching through social contacts and wages, indicating

\footnotetext{
${ }^{22}$ Table A5 reports the estimates of the distribution of unobserved heterogeneity. Compared to the baseline, there is a group of individuals who are more likely to be observed as non-employed, are less likely to exit non-employment conditional on being non-employed, and receive lower wages once they exit employment. There is also another group, which is less likely to enter non-employment and is more likely to find a job with higher wages.
} 
heterogeneity by skill level and relationship type, and underline the importance of controlling for selection into employment.

It is important to note that while there is heterogeneity in the wage effects of network quality by skill level and by type of relationship, the effect of network quality on the probability of finding a job is positive and significant for both skill levels and irrespective of whether the friend is a relative or not. Table A4 presents the estimates for the transition from non-employment to employment, which indicate that better network quality among non-relatives for the high-skilled has the highest effect on job finding (4.4 p.p.), followed by the one among relatives for the low-skilled (3.5 p.p.).

\subsection{Employment Stability}

Finally, we examine the network effect, and its heterogeneity by skill level, on the probability of falling back into non-employment for those who were non-employed in period $t$ and found a job in period $t+1$. If networks transmit information leading to better matches, then those who find a job through informal contacts should also exhibit lower job separation rates and consequently better employment stability. ${ }^{23}$ We estimate the following equation:

$$
\begin{gathered}
p_{N E} \equiv \operatorname{Pr}\left(E_{i, t+2}=0 \mid E_{i, t}=0, E_{i, t+1}=1\right)= \\
F\left(\alpha_{N E}+X_{i, t+1}^{\prime} \beta_{N E}+\delta_{N E} N E F_{i, t}+\eta_{N E i}\right),
\end{gathered}
$$

which is the probability of being non-employed in $t+2$ for the sample of individuals who found a job between $t$ and $t+1$. The specification is similar to the one used for the wage estimation in equation (7).

Panel A in Table 5 shows the estimates of equation (8) using a linear probability model. When we ignore selection and correlation of network quality with unobserved heterogeneity, we find a negative effect of better network quality on the probability to exit employment, which is significant both on average and by skill level, and independent of whether we consider network quality among relatives and non-relatives. These negative coefficients suggest higher employment stability for better connected workers.

\footnotetext{
${ }^{23}$ We focus on employment stability and not on job stability because the information needed to isolate job separations is in general available for a subset of observations, and this results in small cells once we focus on those who find a job in $t+1$ as we do in this section.
} 
Panel B reports the correlated random effects estimates, which are obtained by extending the model of Section 4.3 including the transition equation (8). Because we estimate equation (8) using the logistic distribution, we report both the coefficients and the marginal effects. After accounting for correlated unobservables, all the coefficient estimates of the number of employed friends are substantially lower and statistically insignificant. From the estimates by skill level (Columns 2 and 4 in Panel B of Table 5) there seems to exist some heterogeneity, similar to the one observed in the estimates for wages, but the coefficients are imprecisely estimated. In particular, the marginal effect associated with the coefficient estimate of network quality for high-skilled is twice the average marginal effect (-0.012 in Column 2 vs. -0.006 in Column 1) and is driven mostly by non-relatives (Column 4). Relative to an unconditional probability to exit employment of 17.4 percent, an additional employed friend for high-skilled respondents (marginal effect equal to -0.01) is associated with 5.7 percent reduction in the probability of exiting employment, but this effect is not statistically significant. In contrast, for the low-skilled with a higher number of employed relatives we obtain a positive coefficient (marginal effect of 0.004), which is associated with lower employment stability, but again this effect is not statistically significant. These effects, although very imprecisely estimated and less sizeable, are qualitatively similar to those reported for wages and provide some additional suggestive evidence for network heterogeneity by skill level and type of relationship also in match quality measured by employment stability.

\section{Conclusion}

The labor market effects of social networks have received considerable attention in recent decades. The literature has identified various mechanisms through which social contacts might influence individual labor market outcomes. The most common view posits that networks transmit information about job opportunities improving the matching process. By facilitating job search, workers in networks with a higher employment rate among their members are more likely to form a job match. In addition, because of improved bargaining power, they may also obtain a better match through higher starting wages. However, the matching quality effect of networks is more controversial because of potential mismatch between the information transmitted through the network and the skills possessed by the workers. Networks with more similarity among members (homophily) are 
more likely to improve match quality compared to networks with higher heterogeneity among network members. The empirical literature has produced mixed evidence, with studies finding both positive and negative effects on wages.

In this paper we contribute empirically to the literature by estimating the effect of a direct measure of network quality, based on the number of employed friends, on job finding and match quality using longitudinal data from the BHPS. Using three identification strategies, we provide robust evidence that better network quality has a positive and significant effect on the job finding rate. In particular, one additional employed friend increases the job finding probability by 3.1 percentage points, which corresponds to an increase in the job finding rate by as much as 15 percent. We also find that network quality increases job match quality for high-skilled workers whose networks are characterized by higher degree of homophily; these are networks formed among nonfamilial contacts. Instead, networks formed among familial contacts appear to lead to lower quality jobs for low-skilled workers. In particular, an additional employed (non-relative) friend among highskilled workers leads to a wage premium (a statistically significant 6.1 percent wage increase for each employed friend), while an additional employed relative among low-skilled leads to a wage penalty (a 4.3 percent wage loss for each employed relative, which is not statistically significant). Results on employment stability indicate qualitatively similar heterogeneity by skill level with a positive effect for the high-skilled and a negative effect for the low-skilled. However, the effects on employment stability are imprecisely estimated.

These findings on match quality reconcile previous mixed empirical evidence on the use of contacts as a search channel. Although our data do not provide information on direct referrals, these results are also related to that literature because referrals from familial vs. non-familial contacts may affect individuals differently in terms of labor market outcomes (e.g. Brown et al., 2012; Kramarz and Nordström Skans, 2014). Familial contacts may offer opportunities in jobs which require different skills from the ones job searchers possess, lowering match quality. 


\section{References}

Bayer, P., S.L. Ross, and G. Topa (2008). Place of Work and Place of Residence: Informal Hiring Networks and Labor Market Outcomes. Journal of Political Economy 116(6), 1150-1196.

Beaman, L.A. (2012). Social Networks and the Dynamics of Labor Market Outcomes: Evidence from Refugees Resettled in the U.S. Review of Economic Studies 79(1), 128-171.

Bentolila, S., C. Michelacci, and J. Suarez (2010). Social Contacts and Occupational Choice. Economica 77, 20-45.

Blume, L.E., W.A. Brock, S.N. Durlauf, and Y.M. Ioannides (2011). Identification of Social Interactions in Benhabib, J., A. Bisin, and M.O. Jackson (eds), Handbook of Social Economics, Volume 1B, Elsevier North Holland.

Bramoullé, Y., and G. Saint-Paul (2009). Social Networks and Labor Market Transitions. Labour Economics 17(1), 188-195.

Bramoullé, Y., H. Djebbari, and B. Fortin (2009). Identification of Peer Effects Through Social Networks. Journal of Econometrics 150(1), 41-55.

Brown, M., E. Setren, and G. Topa (2012). Do Referrals Lead to Better Matches? Evidence from a Firm’s Employee Referral System. Federal Reserve Bank of New York, Staff Report No. 568.

Cahuc P., and F. Fontaine (2009). On the Efficiency of Job Search with Social Networks. Journal of Public Economic Theory 11(3), 411-439.

Calvó-Armengol, A. (2004). Job Contact Networks. Journal of Economic Theory 115(1), 191-206.

Calvó-Armengol, A., and M.O. Jackson (2004). The Effects of Social Networks on Employment and Inequality. American Economic Review 94(3), 426-454.

Calvó-Armengol, A., and Y. Zenou (2005). Job Matching Social Networks and Word-of-Mouth Communication. Journal of Urban Economics 57, 500-522.

Calvó-Armengol, A., E. Patacchini, and Y. Zenou (2009). Peer Effects and Social Networks in Education. Review of Economic Studies 76, 1239-1267.

Chamberlain, G. (1984). Panel Data, in Griliches, Z. and M.D. Intriligator (eds), Handbook of Econometrics, Vol. 2, Amsterdam: Elsevier North Holland.

Cingano, F., and A. Rosolia (2012). People I Know: Workplace Networks and Job Search Outcomes. Journal of Labor Economics 30(2), 291-332.

Conti, G., A. Galeotti, G. Mueller, and S. Pudney (2013). Popularity. Journal of Human Resources 48(4), 1072-1094.

Dhillon A., V. Iversen, and G. Torsvik (2013). Employee Referral, Social Proximity and Worker Discipline: Theory and Evidence from India. CESifo Working Paper No. 4309.

Dustmann, C., A. Glitz, and U. Schönberg (2011). Referral-Based Job Search Networks. IZA Discussion Paper No. 5777. 
Edin, P., P. Fredriksson, and O. Åslund (2003). Ethnic Enclaves And The Economic Success Of Immigrants - Evidence From A Natural Experiment. Quarterly Journal of Economics 118(1), 329-357.

Fontaine, F. (2008). Why are Similar Workers Paid Differently? The Role of Social Networks. Journal of Economic Dynamics and Control 32, 3960-3977.

Galenianos M. (2014). Hiring Through Referrals. Journal of Economic Theory 152, 304-323.

Galeotti, A. and Merlino L.P. (2014). Endogenous Job Contact Networks. International Economic Review 55(4), 1201-1226.

Granovetter, M. (1995). Getting a Job: A Study of Contacts and Careers. Second Edition, University of Chicago Press: Chicago.

Hannan, C. (1999). Beyond Networks: 'Social Cohesion’ and Unemployment Exit Rates. ISER Working Paper No. 1999-07, University of Essex.

Heckman, J.J. (1981). The Incidental Parameters Problem and the Problem of Initial Condition in Estimating a Discrete-Time Data Stochastic Process, In Structural Analysis of Discrete Data with Econometric Applications, Manski, C.F., and D. McFadden (eds), MIT: Cambridge, MA.

Heckman, J.J. and B. Singer (1984). A Method for Minimizing the Impact of Distributional Assumptions in Econometric Models for Duration Data. Econometrica 52, 271-230.

Hellerstein, J.M., M. McInerney, and D. Neumark (2011). Neighbors and Co-Workers: The Importance of Residential Labor Market Networks. Journal of Labor Economics 29(4), 659695.

Holzer, H.J. (1988). Search Method Use by Unemployed Youth. Journal of Labor Economics 6(1), $1-20$.

Horváth, G. (2014). Occupational Mismatch and Social Networks. Journal of Economic Behavior and Organization 106, 442-468.

Ioannides, Y.M., and L.D. Loury (2004). Job Information Networks, Neighborhood Effects, and Inequality. Journal of Economic Literature 42(4), 1056-1093.

Ioannides, Y.M. and Soetevent, A.R. (2006). Wages and Employment in a Random Social Network with Arbitrary Degree Distribution. American Economic Review Papers and Proceedings 96(2), 270-274.

Kramarz, F., and O. Nordström Skans (2014). When Strong Ties are Strong: Networks and Youth Labor Market Entry. Review of Economic Studies 81(3), 1164-1200.

Kugler, A. (2003). Employee Referrals and Efficiency Wages. Labour Economics 10, 531-556.

Loury, L.D. (2006). Some Contacts Are More Equal than Others: Informal Networks, Job Tenure, and Wages. Journal of Labor Economics 24(2), 299-318.

Manski, C.F. (1993). Identification of Endogenous Social Effects: The Reflection Problem. Review of Economic Studies 60(3), 531-542. 
Marmaros, D., and B. Sacerdote (2002). Peer and Social Networks in Job Search. European Economic Review 46(4-5), 870-879.

Moffitt, R.A. (2001). Policy Interventions, Low-Level Equilibria, and Social Interactions, in Durlauf, S.N., and H. Peyton Young (eds), Social Dynamics, Cambridge MA: MIT Press.

Montgomery, J.D. (1991). Social Networks and Labor-Market Outcomes: Toward an Economic Analysis. American Economic Review 81(5), 1408-1418.

Montgomery, J.D. (1992). Job Search and Network Composition: Implications of the Strength-OfWeak-Ties Hypothesis. American Sociological Review 57(5), 586-596.

Mortensen D., and T. Vishwanath (1994). Personal Contacts and Earnings. It is Who you Know! Labour Economics 1, 187-201.

Mroz, T.A., and T.H. Savage (2006). The Long-Term Effects of Youth Unemployment. Journal of Human Resources 41(2), 259-293.

Mundlack, Y. (1978). On the Pooling of Time Series and Cross-Sectional Data. Econometrica 46, 69-85.

Munshi, K. (2003). Networks in the Modern Economy: Mexican Migrants in the U.S. Labor Market. Quarterly Journal of Economics 118(2), 549-599.

Pellizzari, M. (2010). Do Friends and Relatives Really Help in Getting a Good Job? Industrial and Labor Relations Review 63(3), 494-510.

Pistaferri, L. (1999). Informal Networks in the Italian Labor Market. Giornale degli Economisti 58(3-4), 355-375.

Saloner, G. (1985). Old Boy Networks as Screening Mechanisms. Journal of Labor Economics 3 (3), 255-267.

Schmutte, I.M. (2015). Job Referral Networks and the Determination of Earnings in Local Labor Markets. Journal of Labor Economics 33(1), 1-32.

Simon, C.J., and J.T. Warner (1992). Matchmaker, Matchmaker: The Effect of Old Boy Networks on Job Match Quality, Earnings, and Tenure. Journal of Labor Economics 10(3), 306-330.

Topa, G. (2001). Social Interactions, Local Spillovers and Unemployment. Review of Economic Studies 68(2), 261-295.

Topa, G. (2011). Labor Markets and Referrals, in Benhabib, J., A. Bisin, and M.O. Jackson, (eds.), Handbook of Social Economics, Vol. 1, Amsterdam: Elsevier North Holland.

Wahba, J., and Y. Zenou (2005). Density, Social Networks and Job Search Methods: Theory and Application to Egypt. Journal of Development Economics 78, 443-473.

Weinberg, B.A., P.B. Reagan, and J.J. Yankow (2004). Do Neighborhoods Affect Hours Worked? Evidence from Longitudinal Data. Journal of Labor Economics 22(4), 891-924. 
Panel A. Full Sample

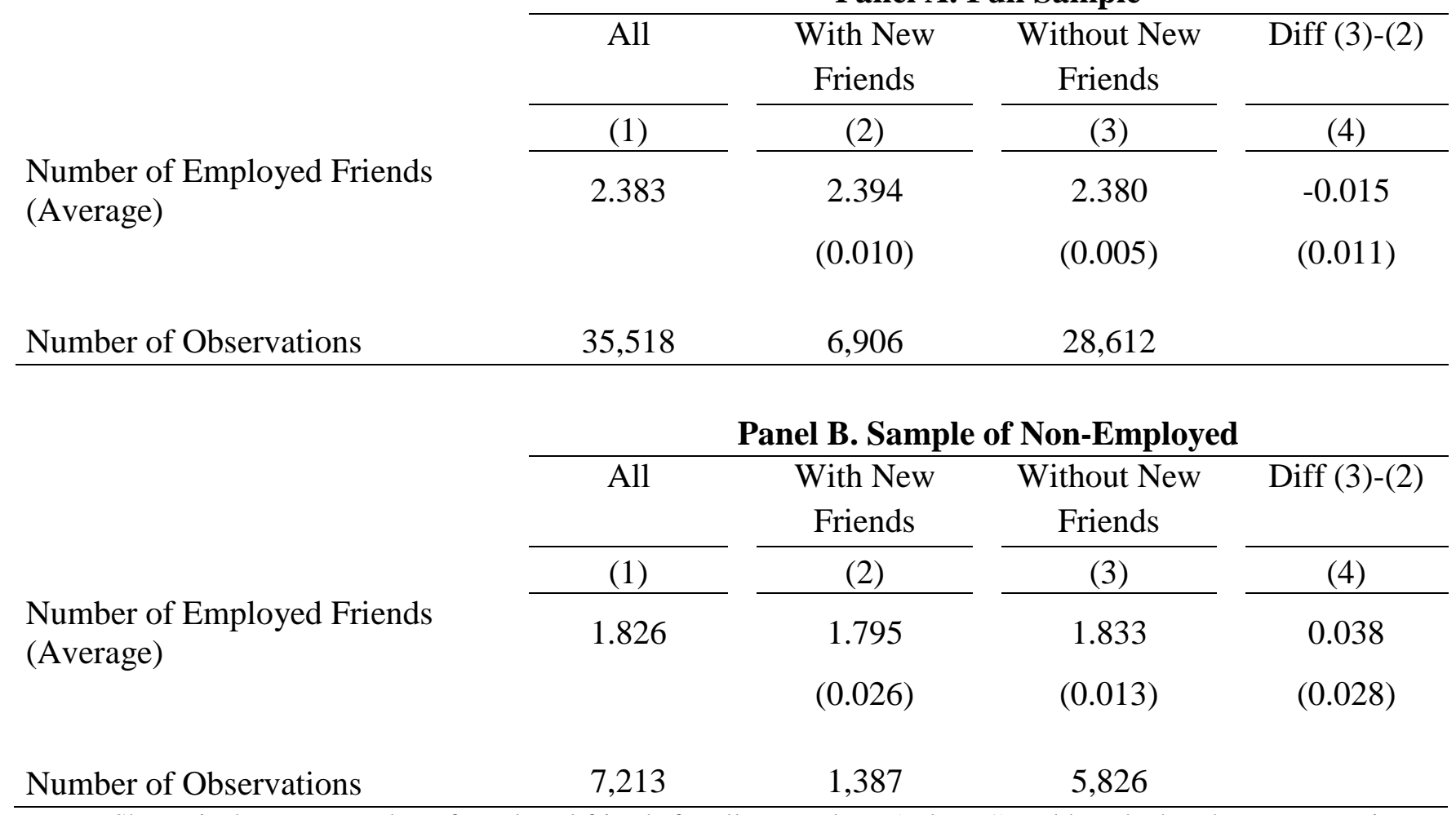

Note: Shown is the mean number of employed friends for all respondents (column1) and by whether they are reporting a new friend (columns 2 and 3). A friend is defined as "new" if the length of friendship is less than 1 year. Column 4 reports the difference in the average number of employed friends between those without and those with at least one new friend. Panel A refers to the full sample, while Panel B to the sample of the non-employed. Standard errors are reported in parentheses. 
Table 2. Transition into Employment by Number of Employed Friends

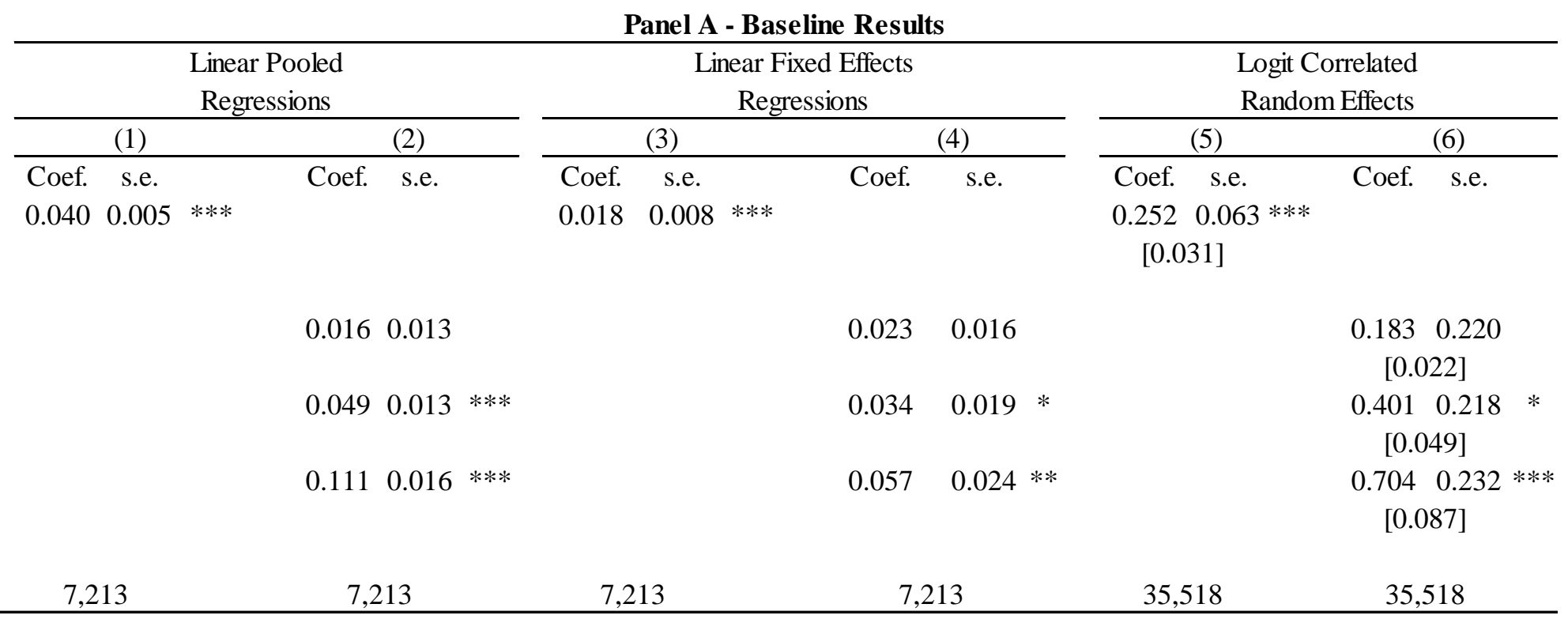

Number of Employed Friends $0.0400 .005 * * *$ Marginal Effect
One Friend Employed

Marginal Effect

Two Friends Employed

Marginal Effect

Three Friends Employed

Marginal Effect

Panel B - Sensitivity Analyses

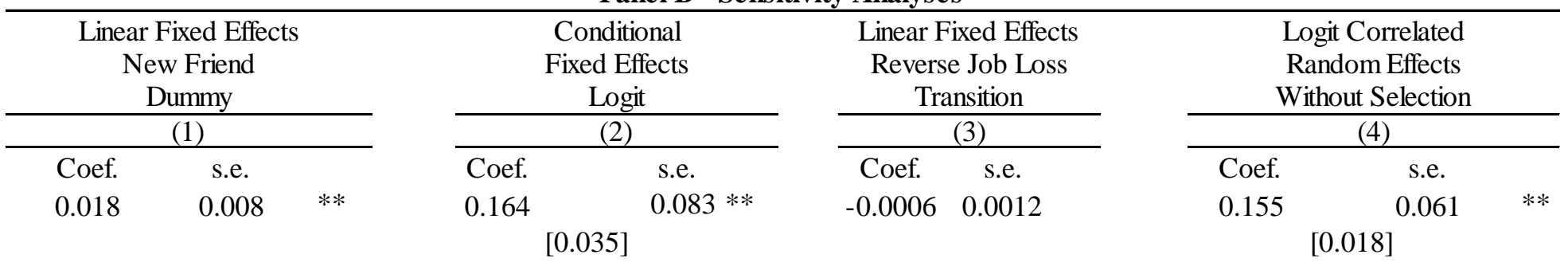

Marginal Effect

$-0.001 \quad 0.026$

Number of Employed Friends

* Having Any New Friend 
Note: In all regressions the sample is based on person-year observations of individuals aged 18-65 in the even years of the period 1992-2006, when information on their three closest friends is available. The sample is also restricted to friends aged 18-65. The sample in columns 1-4 of Panel A and columns 1 and 2 of Panel B is further restricted to non-employed person-year observations. The sample in columns 5 and 6 of Panel A and column 4 of Panel B includes the full sample of observations. Finally, the sample in column 3 of Panel B is restricted to employed person-year observations. Other regressors include individual time-varying covariates (five age group dummies, elapsed duration, dummies for living as a couple, number of children (1, 2 or more), having health problems, experiencing depression, smoking, time and region dummies), individual time-invariant covariates (female dummy, dummies for the level of education, ethnicity dummies) and local economic conditions (local unemployment rate at travel-to-work area). Regressors for friends' characteristics include a female dummy and five age groups dummies for each friend. Standard errors are clustered at the individual level. $* * * / * * / *$ denote significance at the $1 \% / 5 \% / 10 \%$ level, respectively. 


\section{Respondent Employed}

Number of Observations

Instrument: Onset of Health

Related Work Limitation

Marginal Effect

\section{Respondent Employed \\ Marginal Effect}

Panel A - Pooled Linear and Fixed Effects Estimates

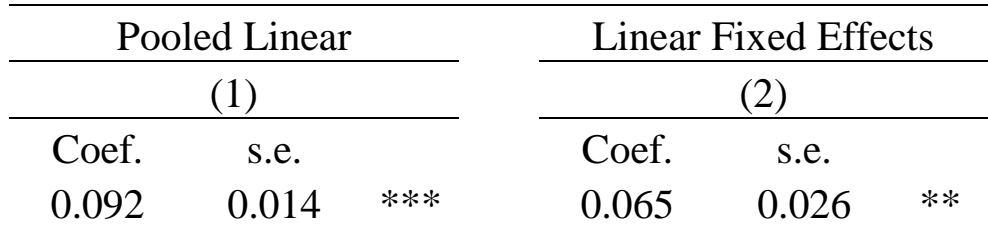

7,219

7,219

Panel B - Instrumental Variables Estimates

FIML IV

FIML IV

W/out Current Health

and Depression

\begin{tabular}{ccc}
\hline \multicolumn{3}{c}{$(1)$} \\
\hline Coef. & s.e. & \\
-0.693 & 0.186 & $* * *$
\end{tabular}

$$
[-0.081]
$$

$[-0.052]$

$0.393 \quad 0.094 * * *$
$[0.075]$
0.381
0.094

(2)

$\begin{array}{ccc}\text { Coef. } & \text { s.e. } \\ -0.450 & 0.188 \quad * *\end{array}$

[0.073]

Number of Observations

7,219

7,219

\begin{abstract}
Note: The sample is defined over the non-employment spells of the respondents' first friend. The dependent variable is a dummy for the transition into employment of the first friend. The variable of interest is "Respondent Employed", which captures whether the respondent is employed or not. Other controls include all the available friend characteristics (age, gender), and the respondents' characteristics which are used as proxies for friends' characteristics that are not available in the BHPS, namely education, family structure, having currently health problems, experiencing depression, smoking, and region of residence. The instrumental variable is a dummy which takes the value one if a respondent experienced a negative health shock that induced the onset of work limitation between $\mathrm{t}-1$ and $\mathrm{t}$, and zero otherwise. Since both the dependent and the endogenous variables are binary, the two equations are estimated jointly with Maximum Likelihood using a logistic distribution allowing for correlated unobserved heterogeneity across the two equations. Average marginal effects are reported in squared brackets below the estimates. $* * * * * * *$ denote significance at the $1 \% / 5 \% / 10 \%$ level, respectively.
\end{abstract}


Table 4. Number of Employed Friends and Hourly Wages by Skill Level and Friends' Relation

Panel A. Pooled Linear Regressions

Number of Employed Friends

Number of Observations

\section{Number of Employed Relatives}

Number of Employed Non-

Relatives

Number of Observations
(1)

\begin{tabular}{cc}
\hline \multicolumn{3}{c}{ Baseline } \\
\hline Coef. & s.e. \\
0.034 & $0.015 \quad * *$ \\
\multicolumn{2}{c}{1,150} \\
\hline
\end{tabular}

(3)

\begin{tabular}{|c|c|c|c|c|c|c|c|}
\hline \multicolumn{3}{|c|}{ Baseline } & \multicolumn{3}{|c|}{ High Skilled } & \multicolumn{2}{|c|}{ Low Skilled } \\
\hline Coef. & s.e. & & Coef. & s.e. & & Coef. & s.e. \\
\hline-0.007 & 0.023 & & -0.009 & 0.034 & & -0.005 & 0.028 \\
\hline 0.046 & 0.016 & $* * *$ & 0.064 & 0.024 & $* * *$ & 0.029 & 0.021 \\
\hline \multicolumn{3}{|c|}{1,130} & \multicolumn{5}{|c|}{1,130} \\
\hline
\end{tabular}

$(2)$

\begin{tabular}{ccccc}
\hline \multicolumn{3}{c}{ High Skilled } & \multicolumn{2}{c}{ Low Skilled } \\
\hline Coef. & s.e. & & Coef. & s.e. \\
0.047 & 0.022 & $* *$ & 0.021 & 0.019 \\
& & 1,150 & & \\
\hline
\end{tabular}

Panel B. FIML

Joint Estimation of the Transition into Employment and Wages Correlated Random Effects with Initial Conditions

(1)

\begin{tabular}{cc}
\hline \multicolumn{2}{c}{ Baseline } \\
\hline Coef. & s.e. \\
0.017 & 0.021 \\
35,518 \\
\hline
\end{tabular}

(3)

\begin{tabular}{|c|c|c|c|c|c|}
\hline \multirow{4}{*}{ Number of Employed Relatives } & \multirow{2}{*}{ Baseline } & \multirow{2}{*}{\multicolumn{2}{|c|}{ High Skilled }} & \multirow{2}{*}{\multicolumn{2}{|c|}{ Low Skilled }} \\
\hline & & & & & \\
\hline & Coef. s.e. & Coef. & s.e. & Coef. & s.e. \\
\hline & $-0.026 \quad 0.032$ & -0.014 & 0.040 & -0.043 & 0.039 \\
\hline \multicolumn{6}{|l|}{ Number of Employed Non- } \\
\hline Relatives & $0.031 \quad 0.021$ & 0.061 & $0.026 * *$ & -0.001 & 0.026 \\
\hline Number of Observations & 34,568 & \multicolumn{4}{|c|}{34,568} \\
\hline
\end{tabular}

Note: Panel A reports results from linear wage regressions restricted on the sample of those who make a transition into employment. Panel B reports results from the wage equation when estimated on the full sample jointly with the transition into employment, and taking into account initial conditions and correlated random effects. Estimations 1 in both panels show the effect of the number of employed friends on wages (Baseline). Estimations 2 in both panels show the effect of the number of employed friends when fully interacted with dummies for the skill level of the respondent (High Skilled vs. Low Skilled). Estimations 3 in both panels distinguish between the effect of the number of employed friends who are relatives vs. the number of employed friends who are non-relatives on wages. Finally, estimations 4 in both panels show the effect by relative status when they are also fully interacted with the skill dummies (combining 2 and 3 ). All estimations include as additional regressors those reported in the note of Table 2. $* * * / * * / *$ denote significance at the $1 \% / 5 \% / 10 \%$ level, respectively. 
Table 5. Number of Employed Friends and Employment Stability by Skill Level and Friends' Relation

Panel A. Pooled Linear Regressions

Number of Employed Friends

Number of Observations

Number of Employed Relatives

Number of Employed Non-

Relatives

Number of Observations
(1)

\begin{tabular}{|c|}
\hline Baseline \\
\hline Coef. \\
\hline $\begin{array}{c}-0.041 \quad 0.014 * * * \\
1,150\end{array}$ \\
\hline
\end{tabular}

(3)

\begin{tabular}{cc}
\hline \multicolumn{3}{c}{ Baseline } \\
\hline Coef. & s.e. \\
-0.043 & $0.020 * *$ \\
-0.042 & $0.015 * * *$
\end{tabular}

1,130
(2)

\begin{tabular}{ccccc}
\hline \multicolumn{3}{c}{ High Skilled } & \multicolumn{2}{c}{ Low Skilled } \\
\hline Coef. & s.e. & & Coef. & s.e. \\
-0.032 & 0.017 & $*$ & -0.051 & 0.020 \\
& & 1,150 & & \\
\hline
\end{tabular}

(4)

\begin{tabular}{cccc}
\hline \multicolumn{3}{c}{ High Skilled } & \multicolumn{2}{c}{ Low Skilled } \\
Coef. & s.e. & Coef. & s.e. \\
-0.026 & 0.025 & -0.058 & 0.029 \\
& & & \\
-0.033 & $0.018 *$ & -0.049 & 0.021
\end{tabular}$* *$

Panel B. Logit FIML

Joint Estimation of the Transition into Employment and Employment Stability Correlated Random Effects with Initial Conditions

(1)

\begin{tabular}{|c|}
\hline Baseline \\
\hline Coef. \\
\hline$-0.112 \quad 0.189$ \\
\hline$[-0.006]$ \\
\hline 35,518 \\
\hline
\end{tabular}

(3)

Number of Employed Friends

Marginal Effect

Number of Observations

Number of Employed Relatives

Marginal Effect

\section{Number of Employed Non-}

\section{Relatives}

Marginal Effect

Number of Observations
(2)

\begin{tabular}{cccc}
\hline \multicolumn{3}{c}{ High Skilled } & \multicolumn{2}{c}{ Low Skilled } \\
\hline Coef. & s.e. & Coef. & s.e. \\
-0.205 & 0.236 & -0.032 & 0.227 \\
{$\left[\begin{array}{ll}-0.012\end{array}\right]$} & {$\left[\begin{array}{ll}-0.002\end{array}\right]$} \\
& 35,518 & \\
\hline
\end{tabular}

(4)

\begin{tabular}{|c|c|c|}
\hline Baseline & High Skilled & Low Skilled \\
\hline Coef. s.e. & Coef. s.e. & Coef. s.e. \\
\hline $0.027 \quad 0.283$ & $\begin{array}{ll}-0.006 & 0.357\end{array}$ & $0.059 \quad 0.335$ \\
\hline [0.002] & {$[-0.0003]$} & [ 0.004] \\
\hline$-0.100 \quad 0.187$ & $-0.171 \quad 0.232$ & $-0.033 \quad 0.228$ \\
\hline$[-0.006]$ & {$[-0.010]$} & {$[-0.002]$} \\
\hline
\end{tabular}

Note: Panel A reports linear regression results from the sample of those who have entered employment. The dependent variable is binary taking the value one if the individual returns back to non-employment within the next year and zero otherwise. Panel B reports the estimation results of the transition back to non-employment when it is estimated on the full sample jointly with the transition into employment, and taking into account initial conditions and correlated random effects. For this joint estimation the transitions are defined using the logistic distribution, and average marginal effects are reported in squared brackets below the estimates. For the description of the specification in each estimation see the note of Table 4. All estimations include as additional regressors those reported in the note of Table 2. $* * * * * * *$ denote significance at the $1 \% / 5 \% / 10 \%$ level, respectively. 


\begin{tabular}{|c|c|c|}
\hline \multirow{3}{*}{ Employment } & \multicolumn{2}{|c|}{ Full Sample } \\
\hline & & St. \\
\hline & Mean & Dev. \\
\hline Employed Currently & 0.797 & 0.402 \\
\hline First Friend Employed Currently & 0.789 & 0.408 \\
\hline Second Friend Employed Currently & 0.795 & 0.403 \\
\hline Third Friend Employed Currently & 0.799 & 0.401 \\
\hline Number of Employed Friends & 2.38 & 0.81 \\
\hline \multicolumn{3}{|l|}{ Demographics } \\
\hline Age & 39.11 & 11.98 \\
\hline Age of First Friend & 39.40 & 12.06 \\
\hline Age of Second Friend & 38.73 & 11.81 \\
\hline Age of Third Friend & 38.49 & 11.87 \\
\hline Dummy for Female & 0.532 & 0.499 \\
\hline Dummy for First Friend Female & 0.547 & 0.498 \\
\hline Dummy for Second Friend Female & 0.575 & 0.494 \\
\hline Dummy for Third Friend Female & 0.569 & 0.495 \\
\hline \multicolumn{3}{|l|}{ Education (Ref: No Educ. Qualifications) } \\
\hline Other Qualifications & 0.083 & 0.275 \\
\hline O-Level & 0.199 & 0.399 \\
\hline A-Level & 0.126 & 0.332 \\
\hline Other Higher Education & 0.293 & 0.455 \\
\hline Degree: First and Higher Education & 0.154 & 0.361 \\
\hline \multicolumn{3}{|l|}{ Family Structure } \\
\hline Dummy for Couples & 0.746 & 0.436 \\
\hline \multicolumn{3}{|l|}{ Number of Children (Ref: No Children) } \\
\hline One Child & 0.168 & 0.374 \\
\hline Two Children & 0.164 & 0.370 \\
\hline Three or More Children & 0.061 & 0.240 \\
\hline \multicolumn{3}{|l|}{ Health Related Variables } \\
\hline Dummy for Having Health Problems & 0.515 & 0.500 \\
\hline Dummy for Experiencing Depresion & 0.063 & 0.243 \\
\hline Dummy for Being a Smoker & 0.277 & 0.448 \\
\hline \multicolumn{3}{|l|}{ Ethnicity (Ref: Other) } \\
\hline White & 0.946 & 0.226 \\
\hline Black African & 0.004 & 0.065 \\
\hline Black Carribean & 0.003 & 0.051 \\
\hline Indian & 0.011 & 0.106 \\
\hline Pakistan & 0.003 & 0.055 \\
\hline Travel-to-Work Unemployment Rate & 4.412 & 3.463 \\
\hline Person-Year Observations & \multicolumn{2}{|c|}{35,518} \\
\hline Number of Persons & \multicolumn{2}{|c|}{9,395} \\
\hline
\end{tabular}


Table A2. Transition into Employment and Residential Mobility

by Number of Employed Friends, Contact Frequency and Residential Proximity

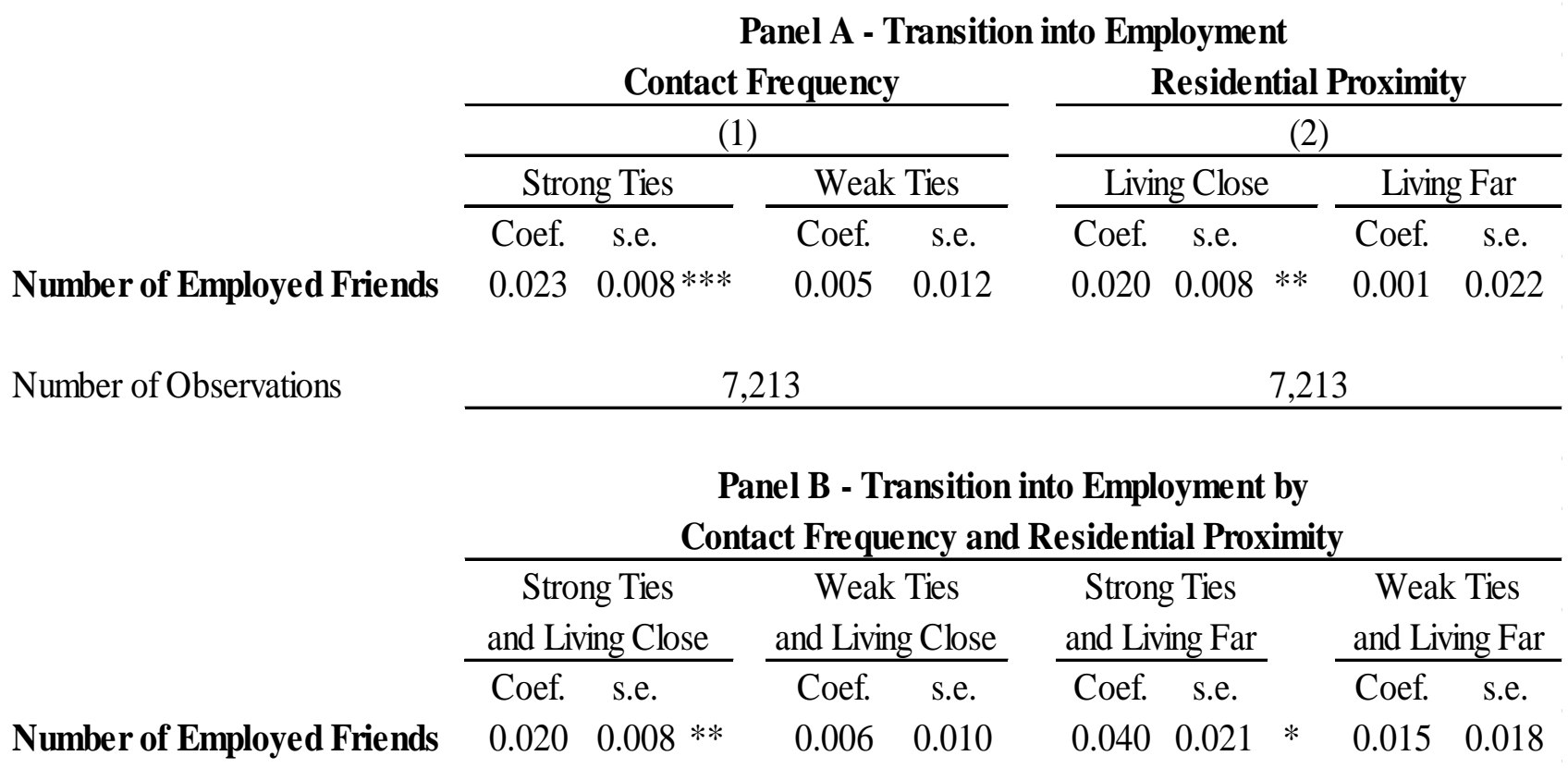

Number of Observations

7,213

Panel C - Transition into Employment with Residential Mobility by Contact Frequency and Residential Proximity

\begin{tabular}{|c|c|c|c|c|}
\hline & $\begin{array}{c}\text { Strong Ties } \\
\text { and Living Close }\end{array}$ & $\begin{array}{c}\text { Weak Ties } \\
\text { and Living Close }\end{array}$ & $\begin{array}{c}\text { Strong Ties } \\
\text { and Living Far }\end{array}$ & $\begin{array}{c}\text { Weak Ties } \\
\text { and Living Far }\end{array}$ \\
\hline & Coef. s.e. & Coef. s.e. & Coef. s.e. & Coef. $\quad$ s.e. \\
\hline
\end{tabular}

Number of Observations

7,213

Note: Panel A shows the linear fixed effects estimates from two separate regressions of the transition into employment. Estimation 1 distinguishes between the number of employed friends with strong and weak ties. "Strong ties" are defined as those in which the frequency of contact either by visiting, writing, or by telephone is at least once a week. "Weak ties" are defined as those in which the frequency of contact is less often than once a week. Estimation 2 distinguishes between the number of employed friends who are living close, or living far. Friends "living close" are defined as those who live up to 50 miles away from the respondent, while friends "living far" are those who live more than 50 miles away from the respondent. Estimation 3 in Panel B distinguishes the number of employed friends by both contact frequency and residential proximity. Estimation 4 in Panel $\mathrm{C}$ is similar to Panel B except that the dependent variable captures transitions into employment combined with residential mobility of the respondent. Residential mobility is based on the question of whether the respondent has moved over the year. For the definition of the sample and the other regressors included in the regressions see the note in Table 2. ***/**/* denote significance at the 1\%/5\%/10\% level, respectively. 


\section{Respondent Employed}

Number of Observations

\section{Instrument: Onset of Health Related Work Limitation}

Marginal Effect

\section{Respondent Employed \\ Marginal Effect \\ Number of Observations}

Panel A - Sample without a New First Friend

\begin{tabular}{|c|c|c|c|c|c|}
\hline \multicolumn{3}{|c|}{ (1) } & \multicolumn{3}{|c|}{$(2)$} \\
\hline \multicolumn{3}{|c|}{ Pooled OLS } & \multicolumn{3}{|c|}{ Fixed Effects } \\
\hline $\begin{array}{l}\text { Coef. } \\
0.093\end{array}$ & $\begin{array}{c}\text { s.e. } \\
0.014\end{array}$ & $* * *$ & $\begin{array}{l}\text { Coef. } \\
0.069\end{array}$ & $\begin{array}{c}\text { s.e. } \\
0.027\end{array}$ & $* * *$ \\
\hline \multicolumn{3}{|c|}{6,940} & \multicolumn{3}{|c|}{6,940} \\
\hline \multicolumn{3}{|c|}{ (3) } & \multicolumn{3}{|c|}{ (4) } \\
\hline \multicolumn{3}{|c|}{$\begin{array}{c}\text { FIML IV } \\
\text { W/out Current Health } \\
\text { and Depression }\end{array}$} & \multicolumn{3}{|c|}{$\begin{array}{c}\text { FIML IV } \\
\text { With Current Health } \\
\text { and Depression } \\
\end{array}$} \\
\hline $\begin{array}{c}\text { Coef. } \\
-0.672\end{array}$ & $\begin{array}{c}\text { s.e. } \\
0.194\end{array}$ & $* * *$ & $\begin{array}{c}\text { Coef. } \\
-0.440\end{array}$ & $\begin{array}{c}\text { s.e. } \\
0.195\end{array}$ & $* *$ \\
\hline \multicolumn{3}{|c|}{$[-0.076]$} & \multicolumn{3}{|c|}{$[-0.050]$} \\
\hline 0.409 & 0.102 & $* * *$ & 0.405 & 0.101 & $* * *$ \\
\hline \multicolumn{3}{|c|}{$[0.078]$} & \multicolumn{3}{|c|}{$[0.078]$} \\
\hline \multicolumn{3}{|c|}{6,940} & \multicolumn{3}{|c|}{6,940} \\
\hline
\end{tabular}

\section{Respondent Employed}

Number of Observations

Instrument: Onset of Health Related Work Limitation

Marginal Effect

\section{Respondent Employed \\ Marginal Effect \\ Number of Observations}

\begin{tabular}{cc}
\hline \multicolumn{3}{c}{ Panel B - Sample w } \\
\hline \multicolumn{2}{c}{$(1)$} \\
\hline \multicolumn{3}{c}{ Pooled OLS } \\
\hline Coef. & s.e. \\
0.098 & $0.020 \quad * * *$ \\
\multicolumn{2}{c}{ 3,605 } \\
\hline
\end{tabular}

(3)

FIML IV

W/out Current Health and Depression

$\begin{array}{ccc}\text { Coef. } & \text { s.e. } & \\ -0.921 & 0.273 & * * *\end{array}$

$[-0.098]$

$0.505 \quad 0.128 * * *$
$[0.098]$

without Any New Friend

(2)

\begin{tabular}{|c|c|c|}
\hline \multicolumn{3}{|c|}{ Fixed Effects } \\
\hline $\begin{array}{l}\text { Coef. } \\
0.080\end{array}$ & $\begin{array}{c}\text { s.e. } \\
0.044\end{array}$ & $*$ \\
\hline & & \\
\hline
\end{tabular}

\section{(4)}

FIML IV

With Current Health and Depression

$\begin{array}{ccc}\text { Coef. } & \text { s.e. } \\ -0.602 & 0.275 \quad * *\end{array}$

$[-0.062]$

$$
0.471 \quad 0.114
$$

Note: The estimations reported in this table are similar to the ones of Table 4. Panel A is restricted to those individuals who do not report a new first friend in the next wave. A friend is defined as "new" if the length of friendship is less than 2 years. Panel B is restricted to individuals who report a first friend in the next even wave of the same gender to the current wave and of age equal to the current age plus two (age next wage $=$ age current +2 ). Average marginal effects are reported in square brackets. $* * * / * * / *$ denote significance at the $1 \% / 5 \% / 10 \%$ level, respectively. 
Table A4. Number of Employed Friends and Transition into Employment

by Skill Level and Friends' Relation

\begin{tabular}{|c|c|c|c|c|c|c|c|c|}
\hline \multirow{4}{*}{$\begin{array}{l}\text { Number of Employed Friends } \\
\text { Marginal Effect }\end{array}$} & \multirow{2}{*}{\multicolumn{3}{|c|}{$\begin{array}{l}(1) \\
\text { All }\end{array}$}} & \multicolumn{5}{|c|}{$(2)$} \\
\hline & & & & \multicolumn{2}{|c|}{ High Skilled } & & \multicolumn{2}{|l|}{ Low Skilled } \\
\hline & $\begin{array}{l}\text { Coef. } \\
0.268\end{array}$ & $\begin{array}{l}\text { s.e. } \\
0.061\end{array}$ & $* * *$ & $\begin{array}{l}\text { Coef. } \\
0.301\end{array}$ & $\begin{array}{l}\text { s.e. } \\
0.077\end{array}$ & $* * *$ & $\begin{array}{lc}\text { Coef. } & \text { s.e. } \\
0.237 & 0.075\end{array}$ & $* * *$ \\
\hline & {$[0$.} & 033] & & {$[0 .($} & 38] & & {$[0.030]$} & \\
\hline \multirow[t]{4}{*}{ Number of Observations } & \multicolumn{3}{|c|}{35,518} & \multicolumn{5}{|c|}{35,518} \\
\hline & \multicolumn{3}{|c|}{ (3) } & \multicolumn{5}{|c|}{ (4) } \\
\hline & \multicolumn{3}{|c|}{ All } & \multicolumn{3}{|c|}{ High Skilled } & \multicolumn{2}{|l|}{ Low Skilled } \\
\hline & $\begin{array}{l}\text { Coef. } \\
0.250\end{array}$ & $\begin{array}{c}\text { s.e. } \\
0.092\end{array}$ & $* * *$ & $\begin{array}{l}\text { Coef. } \\
0.231\end{array}$ & $\begin{array}{c}\text { s.e. } \\
0.115\end{array}$ & $* *$ & $\begin{array}{lc}\text { Coef. } & \text { s.e. } \\
0.261 & 0.111\end{array}$ & $* *$ \\
\hline Marginal Effect & \multicolumn{3}{|c|}{ [0.031] } & \multicolumn{3}{|c|}{$[0.029]$} & {$[0.033]$} & \\
\hline Number of Employed Non-Relatives & 0.274 & 0.063 & $* * *$ & 0.324 & 0.080 & $* * *$ & 0.2270 .078 & $* * *$ \\
\hline Marginal Effect & \multicolumn{3}{|c|}{$[0.034]$} & \multicolumn{3}{|c|}{$[0.041]$} & {$[0.028]$} & \\
\hline Number of Observations & \multicolumn{3}{|c|}{34,568} & \multicolumn{5}{|c|}{34,568} \\
\hline
\end{tabular}

Note: The sample consists of individuals aged 18-65 in the even years of the period 1992-2006 when information on their three reported close friends is available. The sample is also restricted to friends aged 18-65. Other regressors are similar to those reported in Table 2. High skilled are defined as those with A-levels or higher education. Average marginal effects are reported in square brackets. $* * * / * * / *$ denote significance at the $1 \% / 5 \% / 10 \%$ level, respectively. 


\begin{tabular}{|c|c|c|c|c|c|c|c|c|c|}
\hline & Mass Point 1 & s.e. & & Mass Point 2 & s.e. & & Mass Point 3 & s.e. & \\
\hline Non-Employment Transition & -0.212 & 0.514 & & -2.135 & 0.137 & $* * *$ & 2.359 & 0.179 & $* * *$ \\
\hline Initial Conditions Equation & 1.526 & 0.352 & $* * *$ & 2.751 & 0.087 & $* * *$ & -2.865 & 0.089 & $* * *$ \\
\hline Wage Equation & 1.030 & 0.165 & $* * *$ & -0.288 & 0.053 & $* * *$ & 0.096 & 0.055 & $*$ \\
\hline Probability 1 & \multicolumn{9}{|c|}{0.44} \\
\hline Probability 2 & \multicolumn{9}{|c|}{0.12} \\
\hline Probability 3 & \multicolumn{9}{|c|}{0.44} \\
\hline
\end{tabular}

